\title{
Precipitation Results for AN-102: A Statistically Designed Approach to Evaluate Filterability and Sr/TRU Decontamination
}

by

B. Skwarek/Contact

Westinghouse Savannah River Company

Savannah River Site

Aiken, South Carolina 29808

R. A. Dewberry

D. P. DiPrete

T. B. Edwards

S. J. Emory

C. A. Nash

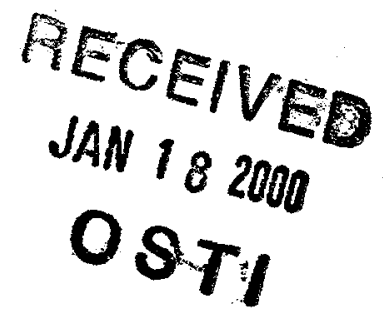

S. C. Smith

W. R. Wilmarth

This paper was prepared in connection with work done under the above contract number with the U.S.

Department of Energy. By acceptance of this paper, the publisher and/or recipient acknowledges the U.S.

Government's right to retain a nonexclusive, royalty-free license in and to any copyright covering this paper, along with the right to reproduce and to authorize others to reproduce all or part of the copyrighted paper. 
WSR-TR-99-00449

BNF-003-98-0161

Precipitation Results for AN-102: A Statistically Designed Approach to Evaluate Filterability and $\mathrm{Sr} / \mathrm{TRU}$ Decontamination.

S.W. Rosencrance

R.A. Dewberry

D.P. DiPrete

T. B. Edwards

S.J. Emory

C.A. Nash

S.C. Smith

W.R. Wilmarth

September 31, 1999

Westinghouse

Savannah River Company

Aiken, SC 29808 


\section{DISCLAIMER}

Portions of this document may be illegible in electronic image products. Images are produced from the best available original document. 


\section{DISCLAIMER}

This report was prepared as an account of work sponsored by an agency of the United States Government. Neither the United States Government nor any agency thereof, nor any of their employees, makes any warranty, express or implied, or assumes any legal liability or responsibility for the accuracy, completeness, or usefulness of any information, apparatus, product or process disclosed, or represents that its use would not infringe privately owned rights. Reference herein to any specific commercial product, process or service by trade name, trademark, manufacturer, or otherwise does not necessarily constitute or imply its endorsement, recommendation, or favoring by the United States Government or any agency thereof. The views and opinions of authors expressed herein do not necessarily state or reflect those of the United States Government or any agency thereof.

This report has been reproduced directly from the best available copy.

Available for sale to the public, in paper, from: U.S. Department of Commerce, National Technical Information Service, 5285 Port Royal Road, Springfield, VA 22161, phone: (800) 553-6847

fax: (703) 605-6900

email: orders@ntis.fedworld.gov

online ordering: http://www.ntis.gov/ordering.htm

Available electronically at http://www.doe.gov/bridge

Available for a processing fee to U.S. Department of Energy and its contractors, in paper, from: U.S. Department of Energy, Office of Scientific and Technical Information, P.O. Box 62, Oak Ridge, TN 37831-0062, phone: (865) 576-8401

fax: (865) 576-5728

email: reports@adonis.osti.gov 
Table of Contents

LIST OF FIGURES.

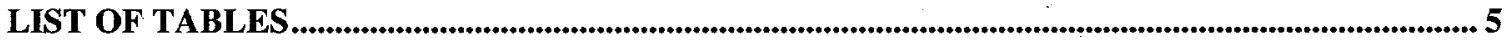

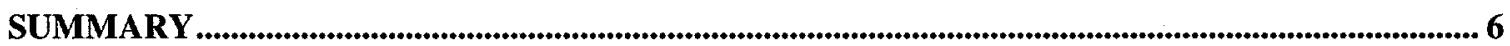

INTRODUCTION

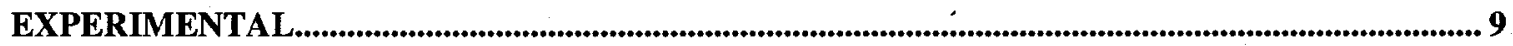

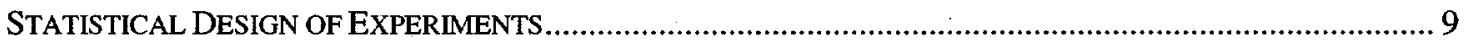

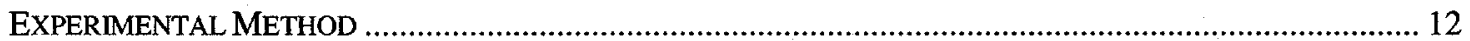

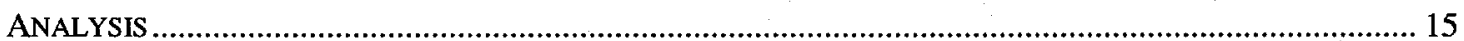

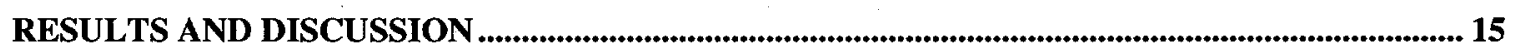

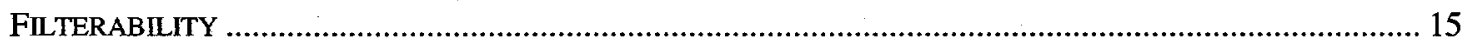

Filterability Data

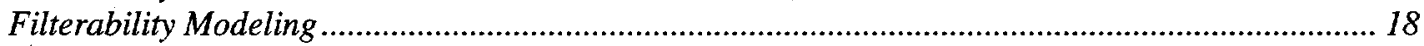

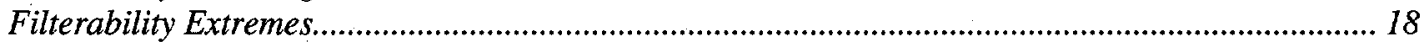

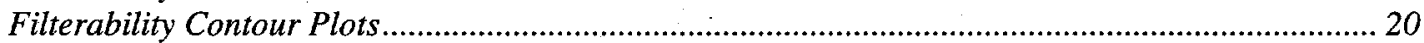

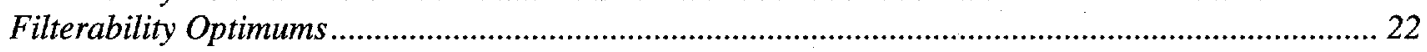

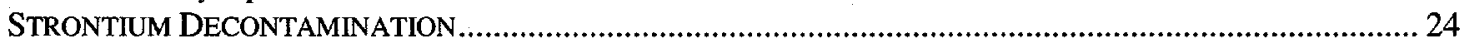

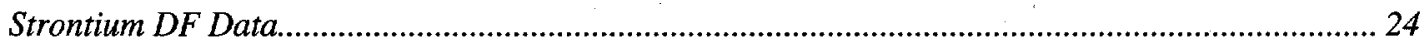

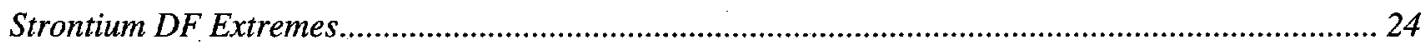

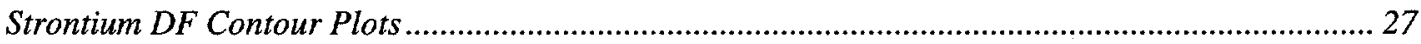

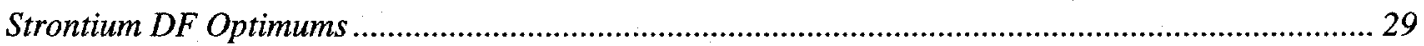

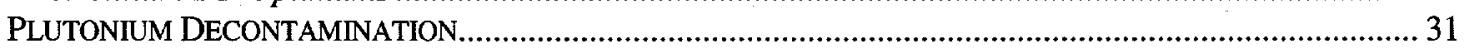

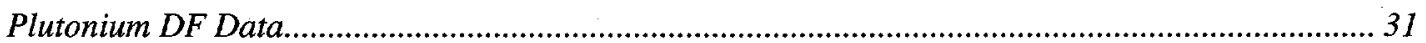

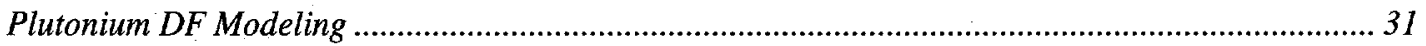

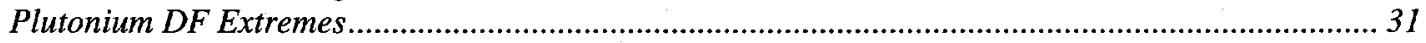

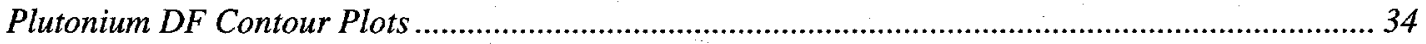

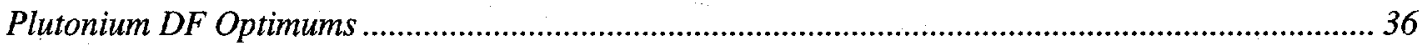

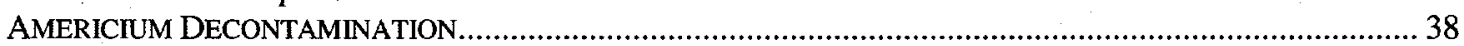

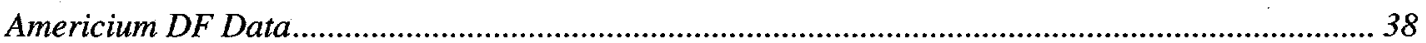

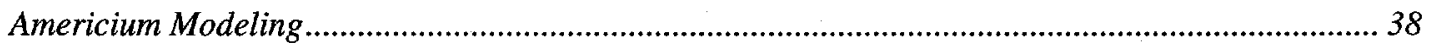

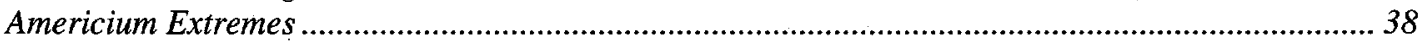

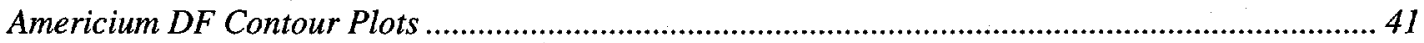

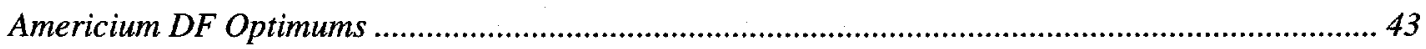

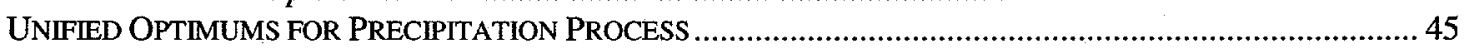

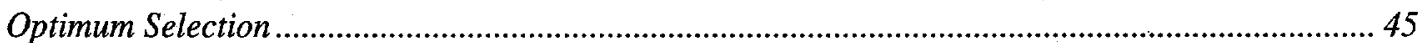

Experimental Results at Unified Optimum Conditions .......................................................................... 46

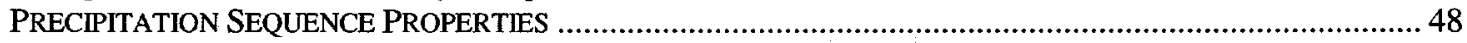

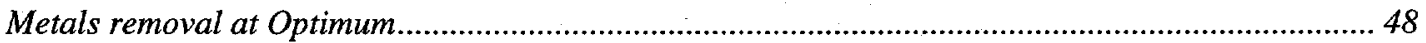

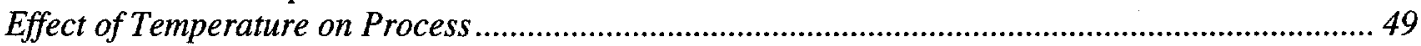

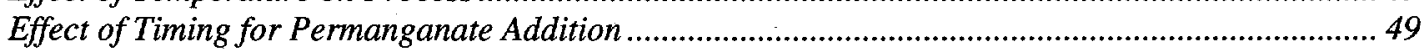

Effect of Entrained Solids on Precipitation Process ...................................................................... 50

CONCLUSIONS................................................................................................................................................ 51

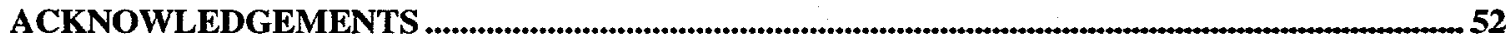

REFERENCES

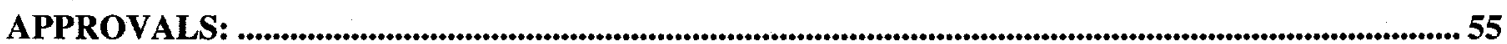




\section{List of Figures}

FIGURE 1 EXPERIMENTAL SCHEMATIC

FIGURE 2. FILTRATE MASS VS. VOLUME CORRELATION FOR FILTERABILITY TESTS

FIGURE 3. PREDICTED VS. MEASURED FLLTERABILITY

FIGURE 4. CONTOUR PLOT OF FILTERABILITY AS A FUNCTION OF SR AND MN ……............20

FIGURE 5. CONTOUR PLOT OF FILTERABILITY AS A FUNCTION OF SR AND NA .................... 21

FIGURE 6. CONTOUR PLOT OF FILTERABILITY AS A FUNCTION OF MN AND NA................... 21

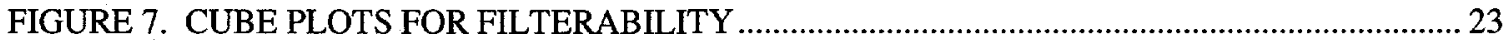

FIGURE 8. PREDICTED VS. MEASURED SR-90 DECONTAMINATION FACTORS ......................... 26

FIGURE 9. CONTOUR PLOT OF SR-90 DF AS A FUNCTION OF SR AND MN ...............................22

FIGURE 10. CONTOUR PLOT OF SR-90 DF AS A FUNCTION OF SR AND NA ……........................ 28

FIGURE 11. CONTOUR PLOT OF SR-90 DF AS A FUNCTION OF NA AND MN ............................. 28

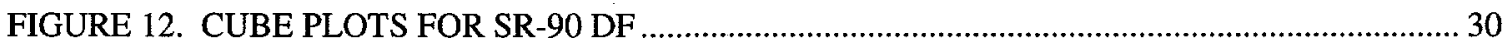

FIGURE 13. PREDICTED VS. MEASURED PU DECONTAMINATION FACTORS ........................... 33

FIGURE 14. CONTOUR PLOT OF PU DF AS A FUNCTION OF CA AND OH.................................... 34

FIGURE 15. CONTOUR PLOT OF PU DF AS A FUNCTION OF SR AND OH ................................... 35

FIGURE 16. CONTOUR PLOT OF PU DF AS A FUNCTION OF CA AND SR ….............................. 35

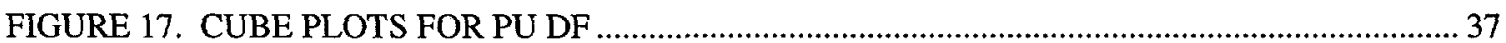

FIGURE 18. PREDICTED VS. MEASURED AM DECONTAMINATION FACTORS ........................... 40

FIGURE 19. CONTOUR PLOT OF AM DF AS A FUNCTION OF SR AND OH ................................... 41

FIGURE 20. CONTOUR PLOT OF AM DF AS A FUNCTION OF NA AND OH ................................. 42

FIGURE 21. CONTOUR PLOT OF AM DF AS A FUNCTION OF NA AND SR …............................... 42

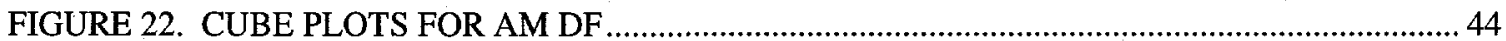




\section{List of Tables}

TABLE 1. EXPERIMENTAL DESIGN 10

TABLE 2. EXPERIMENTAL SEQUENCE 11

TABLE 3. LEVELS OF VARIABLES FOR EXPERIMENTS 13

TABLE 4. PREPARATION RECIPES FOR AN-102 FEED SOLUTIONS …....................................... 13

TABLE 5. MEASURED SODIUM LEVELS FOR FIVE FEED SOLUTIONS ……................................. 14

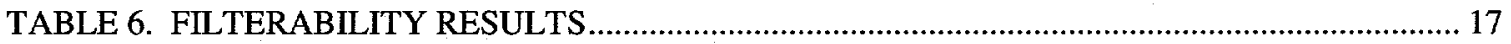

TABLE 7. STATISTICAL ANALYSIS RESULTS FOR FILTERABILITY ………............................... 18

TABLE 8. PARAMETER LEVELS FOR EXTREME FILTERABILITY ………...................................... 20

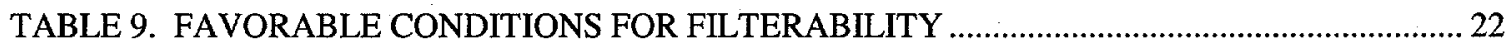

TABLE 10. CALCULATED STRONTIUM-90 DECONTAMINATION FACTORS.................................. 25

TABLE 11. STATISTICAL ANALYSIS RESULTS FOR SR-90 DF ……............................................26

TABLE 12. PARAMETER LEVELS FOR EXTREME SR-90 DF …….............................................. 27

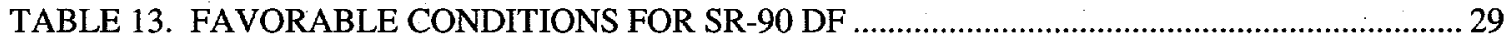

TABLE 14. CALCULATED TOTAL PLUTONIUM DECONTAMINATION FACTORS ........................ 32

TABLE 15. STATISTICAL ANALYSIS RESULTS FOR TOTAL PU DF ………................................. 33

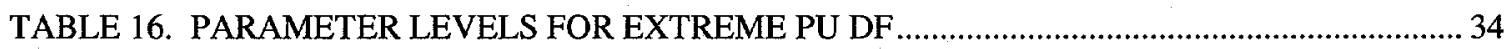

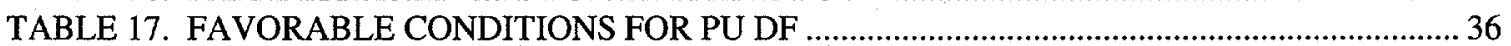

TABLE 18. CALCULATED AM-241 DECONTAMINATION FACTORS …….................................... 39

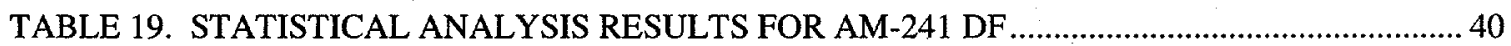

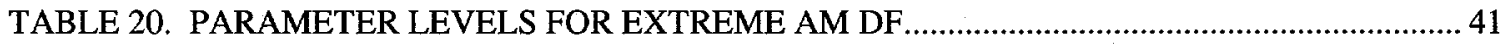

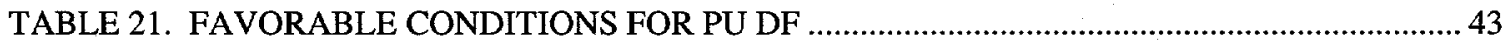

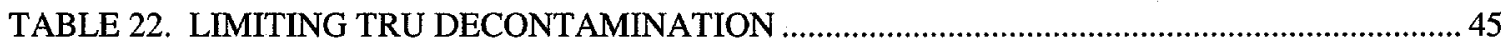

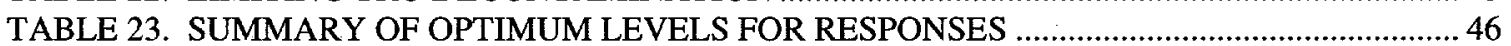

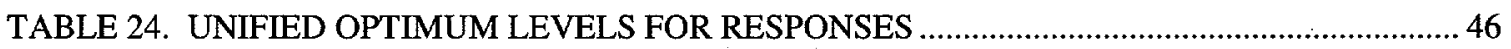

TABLE 25. EXPERIMENTAL RESPONSES AT UNIFIED MODEL OPTIMUMS.................................. 47

TABLE 26. DF FOR VARIOUS METALS AT UNIFIED MODEL OPTIMUMS .................................... 48

TABLE 27. EFFECT OF TEMPERATURE ON PROCESS RESPONSES ……......................................49

TABLE 28. EFFECT OF TIMING ON PROCESS RESPONSES.................................................. 50

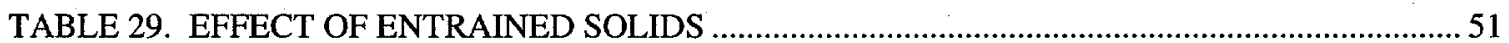




\title{
Precipitation Results for AN-102: A Statistically Designed Approach to Evaluate Filterability and Sr/TRU Decontamination.
}

\author{
S.W. Rosencrance, S.J. Emory, C. A. Nash, S.C. Smith, and W.R. Wilmarth \\ Waste Processing Technology Section \\ R.A. Dewberry and D.P. DiPrete \\ Analytical Development Section \\ T. B. Edwards \\ Statistical Consulting Section \\ Savannah River Technology Center \\ Westinghouse Savannah River Company
}

\section{Summary}

Ultimately, the waste in the various storage tanks at the Hanford reservation will be vitrified. Prior to the vitrification process, a series of pretreatment operations will be performed. Among the key pretreatment processes will be the removal of strontium and transuranic elements from some of the tank wastes (i.e. 241-AN-102 and 241-AN-107). The goal of this pretreatment step is to prepare a product stream that is filterable and decontaminated of both strontium and transuranic elements. The original BNFL precipitation scheme attempted to remove the strontium and transuranic components from the 241-AN-102 and 241-AN-107 supernate via a co-precipitation method. In initial testing, this precipitate was generated using strontium and ferric nitrate additions and was not filterable.

As a result of unacceptable filtration, the need for a new precipitation scheme arose. This newly developed scheme implements a strontium isotopic dilution, a sodium permanganate oxidation, and under certain conditions introduction of calcium to the waste stream.

In order to evaluate the newly developed precipitation process further, a series of experiments were statistically designed. This design examined the relationship between the four responses of primary interest and five precipitation parameters. The four responses of interest are precipitate filterability, strontium decontamination, americium decontamination and plutonium decontamination. The primary precipitation parameters that varied were the initial sodium concentration of the waste, the initial hydroxide level of the waste, and the amounts of calcium, strontium, and permanganate introduced. A limited number of additional experiments were performed to evaluate the impact of other process parameters such as temperature, timing of permanganate addition, and presence of entrained solids on the proposed precipitation scheme. 
Based on this statistically designed series of experiments, models were developed for each of the four responses. The results extracted from these filterability and decontamination models suggest the conditions necessary for optimum performance.

Following are the major conclusions for the conditions evaluated:

- An optimized laboratory precipitation scheme has been determined.

- This optimized scheme has been demonstrated to provide sufficient decontamination for subsequent vitrification studies.

- Temperature has a minimal effect on filterability and decontamination of the slurry

- Entrained solids do not alter the filterability or decontamination thus allowing flexibility in the flowsheet.

- Removal of transition metals such as $\mathrm{Cr}, \mathrm{Ni}$, and $\mathrm{Al}$ is minimal

- Sodium should be at the lowest value tested (6M)

- Hydroxide should be at the highest level examined (1M)

- Strontium addition should be at the highest dose evaluated $(0.075 \mathrm{M})$

- Permanganate should be the highest concentration of the matrix $(0.05 \mathrm{M})$

- Calcium added is inversely proportional to filterability and directly proportional to TRU decontamination. 


\section{Introduction}

Strontium and the actinide elements $\mathrm{Pu}$ and $\mathrm{Am}$ are present in the High Level Liquid Waste in the Hanford tanks 241-AN-102 and 241-AN-107 due to the presence of complexing agents used in the processes within B Plant. ${ }^{1}$ The mission of B Plant from 1967 through 1985 was to recover Sr-90 from Purex Acidified Sludge (PAS) and Purex Current Acid Waste (CAW). B plants mission was also to recover Cs-137 from Redox Neutralized Supernate (RNS), Purex Neutralized Supernate (PNS), Purex Sludge Supernate, and CAW. Sr-90 was separated from the PAS and CAW solutions using a solvent extraction process. The solvent extraction process used di-(2-ethylhexyl) phosphoric acid $\left(\mathrm{D}_{2} \mathrm{EHPA}\right)$ and tributylphosphate (TBP) as the extractant in a normal paraffin hydrocarbon (NPH) diluent. The process was $\mathrm{pH}$ sensitive and required a buffering agent. Hydroxyethylene diamine triacetic acid (HEDTA), ethylene diamine tetraacetic acid (EDTA), and citric acid were added to complex many of the di- and trivalent metals in order to prevent their extraction from the aqueous phase into the organic solvent. The $\mathrm{D}_{2}$ EHPA-TBP-NPH solvent was then washed in several stages before recycle. Among the many species present during these stages were glycolic acid, sodium gluconate, and sodium hydroxide.

The originally proposed BNFL removal process for strontium and transuranic components from 241-AN-102 and 241-AN-107 supernates (Envelope C) was a coprecipitation method. In Part A, tests were performed to decontaminate real waste samples using natural strontium nitrate in an isotopic dilution and ferric nitrate to coprecipitate the actinides. ${ }^{2-5}$ This work was based on earlier investigations by Herting ${ }^{6}$ and Orth, et al. ${ }^{7}$ In general, the results of the experiments indicated a successful decontamination for Sr-90 and the actinides. However, the resulting precipitates could not be filtered. The liquid/solid separation was accomplished by centrifugation.

Following work examined the effects of several factors that potentially influence filtration of the $\mathrm{Sr} / \mathrm{TRU}$ precipitate using the strontium and iron precipitation scheme. The research was performed using statistically designed experiments in a three-phased approach. Variables in the non-radioactive first phase included temperature, sodium ion concentration, hydroxide ion concentration, strontium concentration and total amount, ferric ion concentration and method of addition. A second set of statistically defined experiments examined the influences of the organic components in a simulated Envelope C. The simulant was spiked with Sr-85, Pu-239 and Am-241 tracers. The results of these phases of tests have been recently reported. ${ }^{8}$ The third series of tests were performed by SRTC to further evaluate the iron/strontium precipitation scheme. These tests were conducted using both dead-end filtration and crossflow filtration. The slurry examined was a 241-AN-107 simulant. The conditions included temperature, reagent concentrations, reagent addition order, simulant dilution, and filter aides. ${ }^{9}$ A set of favorable process conditions could not be obtained for the myriad precipitation scheme variations that were examined.

BNFL then requested evaluation of alternative schemes to be used in the precipitation process for removal of Sr/TRU from the envelope C solutions (tanks 241-AN-102 and 
241-AN-107) and provide acceptable filter fluxes. Significant work was performed using new precipitants such as transition metals, lanthanide elements, uranium species, calcium , strontium, and permanganate. These materials were added both individually as well as in various combinations. Of the strategies evaluated only the permanganate containing sequences yielded both sufficient dead-end filterability and decontamination of TRU. The permanganate strategy identified involves a strontium addition as well as an optional calcium addition. ${ }^{9}$

The work reported in this document is a series of statistically designed tests to examine the relationship between the four responses of interest and five precipitation parameters affiliated with the new precipitation scheme. ${ }^{10}$ The four responses are precipitate filterability, strontium decontamination, americium decontamination and plutonium decontamination. The precipitation parameters were the initial sodium concentration of the waste, the initial hydroxide level of the waste, and the amounts of calcium, strontium, and permanganate introduced. Experiments were also performed to evaluate the impact of other process parameters such as temperature, timing of permanganate addition, and presence of entrained solids on the proposed precipitation scheme.

\section{Experimental}

\section{$\underline{\text { Statistical Design of Experiments }}$}

The objective of these experiments was to determine the primary variables that influence filterability, Sr-90 decontamination and TRU decontamination using actual 241-AN-102 waste. $\mathrm{JMP}^{11}$ was used to generate a fractional factorial design. Software validation ${ }^{12}$ was performed on the JMP software used to develop the design. The design consists of 16 experiments to evaluate the high (designated as 1) and low (designated as -1) values of the five variables of primary interest. These 16 experiments support the estimation of the overall average, all major effects, and all two-way interactions. However, fitting a model with these 16 terms only would leave no degrees of freedom for estimating error in the model or experimental process. In addition, a nonlinear response could not be detected or modeled with only these data points.

To address these limitations, the design was modified by adding 9 more experiments. These nine experiments contained intermediate (designated as 0 ) levels of the various parameters. The final design, consisting of 25 experimental trials, is presented in Table 1. This design allows for the investigation of a curvilinear effect due to calcium and/or manganese and for the estimation of process reproducibility. This estimation of error also provides for an opportunity to more thoroughly test for a lack of fit for the fitted models. The order of these experiments was randomized to minimize systematic error contribution from the experimental procedure. Table 2 displays the relation between the conditions of a given experiment in the design and the order in which the experiment was performed and thus the experimental number designation. Also contained in this table are experiments BNFL-15B-EXP-26-B1 and BNFL-15B-EXP-27F4-B1 that were performed to evaluate the effects of addition timing of permanganate and precipitation 
temperature respectively. Experiments BNFL-15B-EXP-4R-B1 and BNFL-15B-EXP13R-B1 are reruns of the corresponding previous experiments. Specifically, BNFL-15BEXP-4R-B1 replaces the original experiment that inadvertently used a damaged filter and BNFL-15B-13R-B1 was simply performed out of numerical sequence. Experiments EXP-14F5-B1 and EXP-18F1-B1 were inadvertently performed using feed three. The design required them to be performed using feeds five and one respectively.

Table 1. Experimental Design

\begin{tabular}{|c|c|c|c|c|c|}
\hline Pattern & [Mn] & [Ca] & $1[\mathrm{OH}]$ & [Sr] & Na] \\
\hline ----+ & -1 & -1 & -1 & -1 & 1 \\
\hline ---+- & -1 & -1 & -1 & 1 & -1 \\
\hline --+-- & -1 & -1 & 1 & -1 & -1 \\
\hline--+++ & -1 & -1 & 1 & 1 & 1 \\
\hline -+--- & -1 & 1 & -1 & -1 & -1 \\
\hline -+-++ & -1 & 1 & -1 & 1 & 1 \\
\hline-++-+ & -1 & 1 & 1 & -1 & 1 \\
\hline -+++- & -1 & 1 & 1 & 1 & -1 \\
\hline +---- & 1 & -1 & -1 & -1 & -1 \\
\hline+--++ & 1 & -1 & -1 & 1 & 1 \\
\hline+-+-+ & 1 & -1 & 1 & -1 & 1 \\
\hline+-++- & 1 & -1 & 1 & 1 & -1 \\
\hline ++--+ & 1 & 1 & -1 & -1 & 1 \\
\hline++-+- & 1 & 1 & -1 & 1 & -1 \\
\hline+++- & 1 & 1 & 1 & -1 & -1 \\
\hline +++++ & 1 & 1 & 1 & 1 & 1 \\
\hline-0000 & -1 & 0 & 0 & 0 & 0 \\
\hline 10000 & 1 & 0 & 0 & 0 & 0 \\
\hline $0-000$ & 0 & -1 & 0 & 0 & 0 \\
\hline $0+000$ & 0 & 1 & 0 & 0 & 0 \\
\hline-0000 & -1 & 0 & 0 & 0 & 0 \\
\hline 10000 & 1 & 0 & 0 & 0 & 0 \\
\hline $0-000$ & 0 & -1 & 0 & 0 & 0 \\
\hline $0+000$ & 0 & 1 & 0 & 0 & 0 \\
\hline 00000 & 0 & 0 & 0 & 0 & 0 \\
\hline
\end{tabular}


Table 2. Experimental Sequence

\begin{tabular}{|c|c|c|c|c|c|c|}
\hline Exp ID & Pattem & {$[\mathrm{Mn}]$} & [Ca] & {$[\mathrm{OH}]$} & {$[\mathrm{Sr}]$} & {$[\mathrm{Na}]$} \\
\hline BNFL-15B-EXP-1-B1 & ++ & 1 & 1 & -1 & 1 & -1 \\
\hline BNFL-15B-EXP-2-B1 & 00000 & 0 & 0 & 0 & 0 & 0 \\
\hline BNFL-15B-EXP-3-B1 & ++-+ & 1 & -1 & 1 & -1 & 1 \\
\hline BNFL-15B-EXP-4-B1 & +++ & 1 & 1 & 1 & -1 & -1 \\
\hline BNFL-15B-EXP-5-B1 & +-+ & -1 & 1 & -1 & 1 & 1 \\
\hline BNFL-15B-EXP-6-B1 & $0-000$ & 0 & -1 & 0 & 0 & 0 \\
\hline BNFL-15B-EXP-7-B1 & + & 1 & -1 & -1 & -1 & -1 \\
\hline BNFL-15B-EXP-8-B1 & $0+000$ & 0 & 1 & 0 & 0 & 0 \\
\hline BNF-15B-EXP-9B1 & $0+000$ & 0 & 1 & 0 & 0 & 0 \\
\hline BNFL-15B-EXP-10-B1 & $0-000$ & 0 & -1 & 0 & 0 & 0 \\
\hline BNFL-15B-EXP-11-B1 & -0000 & -1 & 0 & 0 & 0 & 0 \\
\hline BNFL-15B-EXP-12-B1 & $+1+$ & -1 & -1 & 1 & 1 & 1 \\
\hline BNFL-15B-EXP-14-B1 & $-0+0$ & -1 & -1 & 0 & 1 & 0 \\
\hline BNFL-15B-EXP-15-B1 & 10000 & 1 & 0 & 0 & 0 & 0 \\
\hline BNFL-15B-EXP-16-B1 & $+-1+$ & 1 & -1 & -1 & 1 & 1 \\
\hline BNFL-15B-EXP-17-B1 & + & -1 & 1 & -1 & -1 & -1 \\
\hline BNFL-15B-EXP-18-B1 & +00 & -1 & 1 & 0 & -1 & 0 \\
\hline BNFL-15B-EXP-19-B1 & +4 & 1 & 1 & -1 & -1 & 1 \\
\hline BNFL-15B-EXP-20-B1 & ++1 & 1 & -1 & 1 & 1 & -1 \\
\hline BNFL-15B-EXP-21-B1 & 10000 & 1 & 0 & 0 & 0 & 0 \\
\hline BNFL-15B-EXP-22-B1 & ++ & -1 & 1 & 1 & 1 & -1 \\
\hline BNFL-15B-EXP-23-B1 & $+1+1$ & 1 & 1 & 1 & 1 & $\overline{1}$ \\
\hline BNFL-15B-EXP-24-B1 & + & -1 & -1 & 1 & -1 & -1 \\
\hline BNFL-15B-EXP-26-B1 & 0000 & 0 & -1 & 0 & 0 & 0 \\
\hline BNF-15B-EXP-14F5-B1 & + & -1 & -1 & -1 & 1 & -1 \\
\hline BNFL-15B-EXP-18F1-B1 & +1 & -1 & 1 & 1 & -1 & 1 \\
\hline BNFL-15B-EXP-27F4-B1 & $+1+$ & 1 & -1 & 1 & 1 & -1 \\
\hline BNFL-15B-EXP-13P-B1 & $\longrightarrow$ & -1 & -1 & -1 & -1 & 1 \\
\hline BNFL-15B-EXP-4RB1 & +++ & 1 & 1 & 1 & -1 & -1 \\
\hline
\end{tabular}




\section{Experimental Method}

Shown in Figure 1 is a summary of the experimental procedure used for these real waste beaker tests. In order to reduce error during the experimentation the 25-experiment matrix was grouped according to initial sodium and hydroxide levels of the waste. This grouping allowed a feed solution to be prepared for each of the four corners of the matrix (high sodium-high hydroxide, high sodium-low hydroxide, low sodium-high hydroxide, and low sodium-low hydroxide). Furthermore, a feed solution was prepared for the nine midpoint experiments which all occurred at the intermediate levels of sodium and hydroxide.

\section{Figure 1 Experimental Schematic}

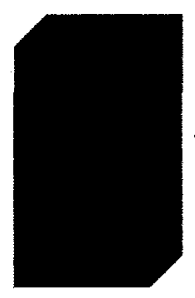

About 1liter

Hanford AN-102

(Envelope C waste)

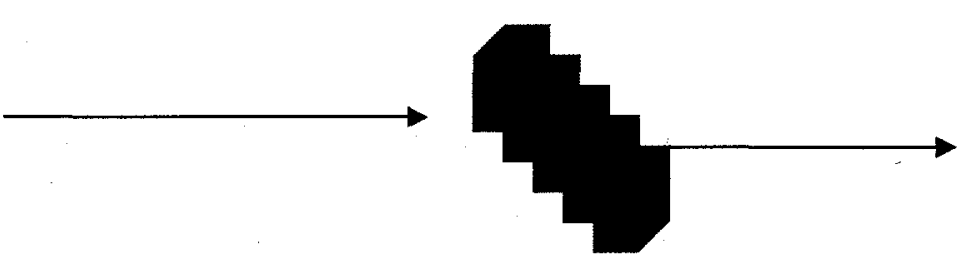

5 solutions prepared with fixed $\mathrm{Na}$ and free $\mathrm{OH}$
* Filterability measured by monitoring filtrate rate through a 0.45 micron nylon cup filter. (Reported as flux)

* Shear using a blender

* Heat using a drying oven
$50 \mathrm{ml}$ is placed in a container

$\mathrm{Ca}, \mathrm{Sr}$, and Mn will be added as needed

Aged for 4 hours at $50 \mathrm{C}$

The solution will be sheared

Measure Filterability

Send Samples to ADS for DF 
The relationships between the absolute values of the experimental variable and the qualitative (high (1), intermediate (0), and low (-1)) levels are shown in Table 3 . These values have been chosen to cover a range of operating conditions that are of practical interest for the BNFL flowsheet and precipitation/ultrafiltration system design.

Table 3. Levels of Variables for Experiments

\begin{tabular}{|c|c|c|c|c|c|c|}
\hline & & $\mathrm{Na}$ & $\mathrm{OH}$ & $\mathrm{Ca}$ & $\mathrm{Sr}$ & $\mathrm{Mn}$ \\
\hline 1 & & 7.0 & 1.0 & .012 & .075 & .05 \\
\hline 0 & & 6.5 & 0.75 & .006 & .05 & .04 \\
\hline-1 & & 6.0 & 0.50 & .000 & .02 & .03 \\
\hline NOTES: & $\begin{array}{l}1 . \\
2 \\
\overline{3} . \\
4 .\end{array}$ & $\begin{array}{l}\text { All values in } \\
\text { Calcium leve } \\
\text { OH is added } \\
\text { Initial }[\mathrm{OH}]\end{array}$ & $\begin{array}{l}\text { units. } \\
\text { vn is add } \\
\text { Mal) hydr } \\
\text { M at } 9 \mathrm{M}\end{array}$ & & $8 \mathrm{M} \mathrm{Ca})$ & \\
\hline
\end{tabular}

The five feed solutions were prepared by adding various amounts of deionized water and $\mathrm{NaOH}$ to the previously composited $241-\mathrm{AN}-102$ sample. ${ }^{13}$ The composited solution was dead-end filtered using a 0.45 micron nylon filter. The sodium level in this initial slurry was determined to be $6.9 \mathrm{M}$ sodium. Discussions with $\mathrm{M}$. Johnson of BNFL noted that the free hydroxide level was about $0.15 \mathrm{M}$. It was concluded that the hydroxide would be added at the levels specified in Table 3. Based on these initial levels of sodium and hydroxide the five feed samples were prepared at the five desired sodium and hydroxide combinations. The details of the feed preparation recipe can be found in Table 4. Enough feed was prepared for two extra experiments for each feed solution based on the matrix in Table 1. For the precipitation experiments performed in the presence of entrained solids a diluted waste solution was used which had not been dead-end filtered at SRTC.

Table 4. Preparation Recipes for AN-102 Feed Solutions

\begin{tabular}{lccccc}
\hline & Feed 1 & Feed 2 & Feed 3 & Feed 4 & Feed 5 \\
& 7M Na & 7M Na & 6.5M Na & 6M Na & 6M Na \\
& 1M OH & $\mathbf{0 . 5 M ~ O H}$ & $\mathbf{0 . 7 5 M ~ O H ~}$ & $\mathbf{1 M ~ O H}$ & $\mathbf{0 . 5 M ~ O H}$ \\
\hline $\mathrm{AN}-102$ & $282.2 \mathrm{ml}$ & $297 \mathrm{ml}$ & $494.5 \mathrm{ml}$ & $234.4 \mathrm{ml}$ & $258.6 \mathrm{ml}$ \\
& & & & & \\
$\mathrm{DI} \mathrm{H}{ }_{2} \mathrm{O}$ & $0 \mathrm{ml}$ & $0 \mathrm{ml}$ & $55.5 \mathrm{ml}$ & $65.6 \mathrm{ml}$ & $41.4 \mathrm{ml}$ \\
$\mathrm{NaOH}$ & $17.8 \mathrm{ml} \mathrm{17M}$ & $6.19 \mathrm{~g}$ & $16.5 \mathrm{~g}$ & $12 \mathrm{~g}$ & $6 \mathrm{~g}$ \\
& & & & & \\
\hline
\end{tabular}


The feeds were sampled and diluted 50:1 in order to facilitate transfer out of the shielded cells facility for analysis. The dilution was performed using $0.1 \mathrm{M} \mathrm{HCl}$ and the sodium levels were measured using atomic absorption (AA) spectroscopy. The sodium values measured for the five feed solutions as well as the targeted values are shown in Table 5. The results shown are the average of three AA measurements with their appropriate $95 \%$ confidence intervals.

Table 5. Measured Sodium Levels for Five Feed Solutions

\begin{tabular}{lccccc}
\hline & Feed 1 & Feed 2 & Feed 3 & Feed 4 & Feed 5 \\
\hline Target [Na] & 7.0 & 7.0 & 6.5 & 6.0 & 6.0 \\
Measured [Na] & $7.0 \pm 0.2$ & $6.9 \pm 0.3$ & $6.4 \pm 0.2$ & $5.8 \pm 0.3$ & $5.6 \pm 0.6$ \\
\hline
\end{tabular}

Each point in experimental matrix corresponds to one of the five feed solutions. $50 \mathrm{ml}$ of the appropriate feed solution was placed in a $125 \mathrm{ml}$ polybottle along with a magnetic stirring bar. The sample was capped and placed in a preheated water bath that was located in the shielded cells on the top of a hot plate. The temperature of the water bath was monitored regularly using a thermometer. The temperature was maintained, unless noted otherwise, at $50+/-5 \mathrm{C}$.

Three precipitants were added at the various levels described in the experimental matrix. The calcium was gravimetrically prepared as a $0.5 \mathrm{M}$ calcium nitrate solution and the same stock solution was used throughout the precipitation series. Likewise a stock solution of $1 \mathrm{M}$ strontium nitrate was gravimetrically prepared and used for the entire series of real waste beaker tests. The sodium permanganate solution was prepared fresh the afternoon prior to the actual precipitation. Each time the permanganate solution was prepared 7.995g of sodium permanganate was added to $50 \mathrm{ml}$ of DI water. All three precipitant solutions were prepared outside of the cells and placed in highly hydrophobic wide-mouth plastic tubes. These tubes were then used to pour the proper dosage of the additives into the feed sample. It was demonstrated that greater than $99 \%$ transfer routinely occurs with this method. This strategy greatly reduced potential addition errors in the shielded cells where many routine activities are quite cumbersome and unpredictable.

Once the $50 \mathrm{ml}$ feed sample was equilibrated at the appropriate temperature the precipitation was initiated. The calcium component was added first. The strontium reagent followed this addition five minutes later and finally after another five-minute period the permanganate was introduced. Three minutes after the permanganate was added the polybottle was gently capped and placed in a preheated drying oven for four 
hours at $50+/-5 \mathrm{C}$. Following this aging period the samples were removed and allowed to cool to $30+/-\mathrm{C}$ prior to the next step in the test.

Once the samples were at room temperature they were subjected to three minutes of intense shear at 8,000 rpm from a Braun handmixer. The Braun handmixer was thoroughly rinsed between each experiment. The high shear of the handmixer was not intended to mimic a specified shear condition, rather to introduce a reproducible extreme shear condition prior to filtration.

The samples were then filtered through a preweighed 0.45 micron nylon dead-end filter for one minute. The volume and mass of filtrate collected during this one minute time period was recorded. A portion of the filtrate was collected and diluted 50:1 using 0.1M $\mathrm{HCl}$. This sample was submitted to analytical various analysis.

\section{$\underline{\text { Analysis }}$}

Samples were submitted to the Analytical Development Section (ADS) of SRTC for analyses. 14 These analyses included elemental analysis by Inductively Coupled Plasma Emission spectroscopy, ${ }^{15}$ Inductively Coupled Plasma - Mass Spectrometry, ${ }^{16}$ gamma spectroscopy, 17 liquid scintillation analysis for strontium-90,18 and alpha pulse height analysis 19 as well as various other analyses. Laboratory notebook WSRC-NB-99-00160 contains data obtained during these tests and the procedures used.

\section{Results and Discussion}

\section{Filterability}

Filterability Data

Table 6 contains the filtration results measured for each of the precipitated and sheared 241-AN-102 samples. The results are reported as both masses and volumes. The mass results were measured on a balance in the shielded cells. The volumes were measured by transferring the filtrate into a $50 \mathrm{ml}$-graduated cylinder and using a monocle to estimate the fluid level. The volume measurements are subject to less accuracy because of poor visual conditions through the glass windows of the shielded cells. From figure 2 it is clear that the volume and mass results track each other very well. Based on this high level of correlation it was concluded that use of either of these observables is acceptable. Because the mass measurements are more reproducible in the cell environment a decision was made to focus on this observable as a means for modeling the filterability:as a: function of the design parameters. 
Figure 2. Filtrate Mass vs. Volume Correlation for Filterability Tests

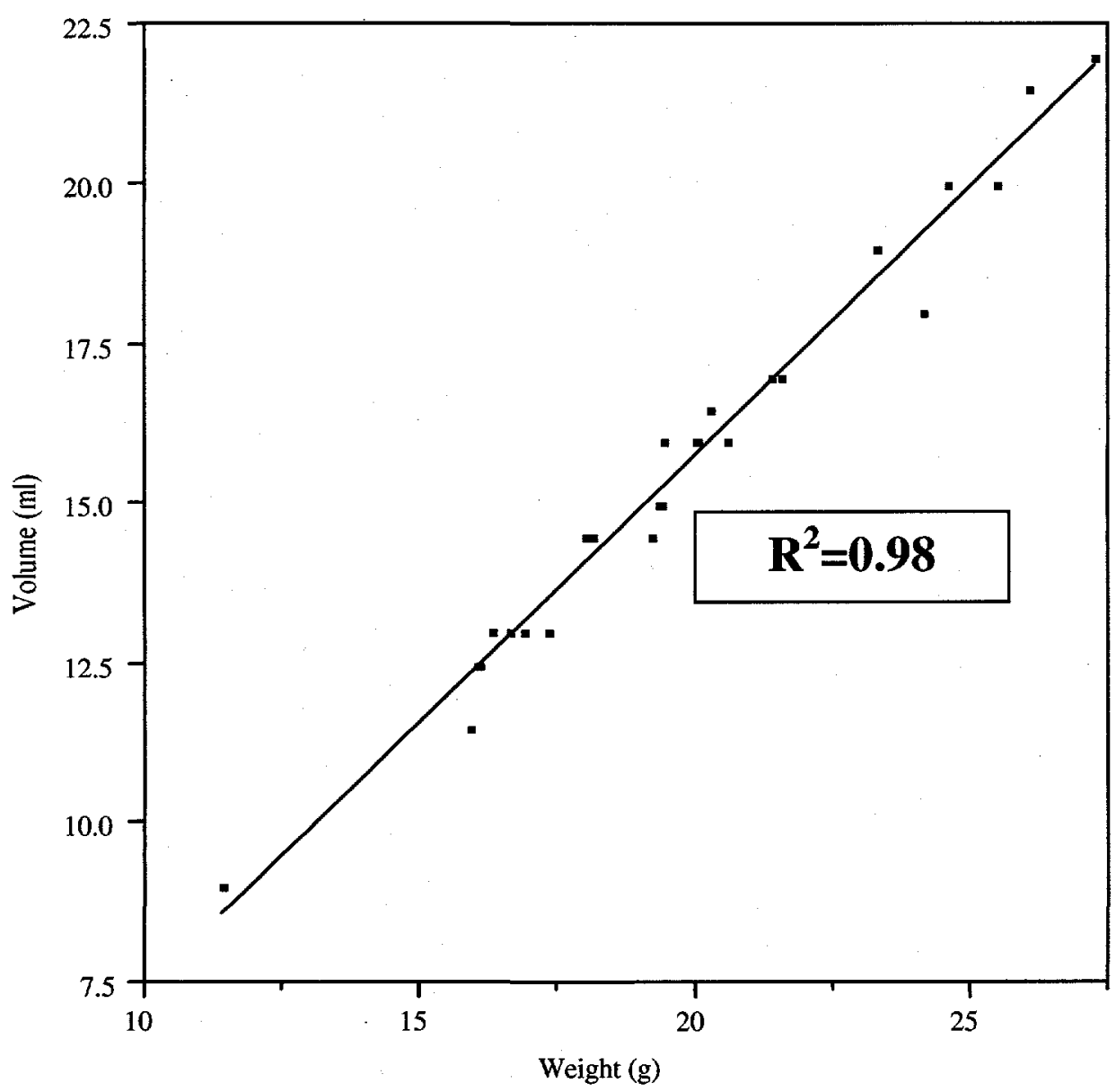


Table 6. Filterability Results

$\begin{array}{ccc}\text { Exp ID } & \text { Volume }(\mathrm{ml}) & \text { Weight }(\mathrm{g}) \\ \text { BNFL-15B-EXP-1-B1 } & 13.0 & 16.33 \\ \text { BNFL-15B-EXP-2-B1 } & 13.0 & 17.36 \\ \text { BNFL-15B-EXP-3-B1 } & 11.5 & 15.95 \\ \text { BNFL-15B-EXP-4-B1 } & - & - \\ \text { BNFL-15B-EXP-5-B1 } & 9.0 & 11.47 \\ \text { BNFL-15B-EXP-6-B1 } & 16.5 & 20.29 \\ \text { BNFL-15B-EXP-7-B1 } & 14.5 & 18.05 \\ \text { BNFL-15B-EXP-8-B1 } & 14.5 & 19.26 \\ \text { BNFL-15B-EXP-9-B1 } & 13.0 & 16.94 \\ \text { BNFL-15B-EXP-10-B1 } & 15.0 & 19.43 \\ \text { BNFL-15B-EXP-11-B1 } & 12.5 & 16.08 \\ \text { BNFL-15B-EXP-12-B1 } & 17.0 & 21.62 \\ \text { BNFL-15B-EXP-14-B1 } & 16.0 & 20.64 \\ \text { BNFL-15B-EXP-15-B1 } & 16.0 & 20.08 \\ \text { BNFL-15B-EXP-16-B1 } & 17.0 & 21.45 \\ \text { BNFL-15B-EXP-17-B1 } & 16.0 & 20.05 \\ \text { BNFL-15B-EXP-18-B1 } & 15.0 & 19.37 \\ \text { BNFL-15B-EXP-19-B1 } & 13.0 & 16.66 \\ \text { BNFL-15B-EXP-20-B1 } & 21.5 & 26.09 \\ \text { BNFL-15B-EXP-21-B1 } & 16.0 & 19.48 \\ \text { BNFL-15B-EXP-22-B1 } & 20.0 & 24.62 \\ \text { BNFL-15B-EXP-23-B1 } & 12.5 & 16.14 \\ \text { BNFL-15B-EXP-24-B1 } & 22.0 & 27.31 \\ \text { BNFL-15B-EXP-26-B1 } & 16.0 & 20.18 \\ \text { BNFL-15B-EXP-14F5-B1 } & 19.0 & 23.35 \\ \text { BNFL-15B-EXP-18F1-B1 } & 20.0 & 25.54 \\ \text { BNFL-15B-EXP-27F4-B1 } & 23.5 & 30.55 \\ \text { BNFL-15B-EXP-13R-B1 } & 14.5 & 18.16 \\ \text { BNFL-15B-EXP-4R-B1 } & 18.0 & 24.17\end{array}$

**As a reference $10 \mathrm{ml} / \mathrm{min}$ converts to $0.06 \mathrm{gpm} / \mathrm{ft} 2$ 
Filterability Modeling

The filterability results were used to perform a statistical analysis. The resulting model relating filterability of the precipitated slurry to the five precipitation parameters is provided in Table 7. The JMP Statistical program, version 3.2.2 was used to fit the filtrate flux data to a linear function of the five variables. Terms that contributed to the model with less than an $85 \%$ confidence were dropped from the model. This strategy allows only the terms that are most likely contributing to a physical description of the filterability to remain. Some primary terms must remain in the model even though their significance of contribution is much less than the $85 \%$ threshold. The retention of these parameters is necessitated by higher order terms of sufficient significance for retention that contain that variable of interest as one of the cross terms.

\section{Table 7. Statistical Analysis Results for Filterability}

$\begin{array}{lrrrr}\text { Term } & \text { Estimate } & \text { Std Error } & \text { t Ratio } & \text { Prob }>|\mathbf{t}| \\ \text { Intercept } & 19.690638 & 0.403723 & 48.77 & <.0001 \\ {[\mathrm{Mn}]} & -0.511698 & 0.449684 & -1.14 & 0.2719 \\ {[\mathrm{Ca}]} & -1.089157 & 0.440793 & -2.47 & 0.0251 \\ {[\mathrm{OH}]} & 2.245 & 0.512155 & 4.38 & 0.0005 \\ {[\mathrm{Mn}]^{*}[\mathrm{OH}]} & -1.011375 & 0.512155 & -1.97 & 0.0658 \\ {[\mathrm{Ca}]^{*}[\mathrm{OH}]} & 1.0005 & 0.512155 & 1.95 & 0.0685 \\ {[\mathrm{Sr}]} & -0.222928 & 0.487868 & -0.46 & 0.6539 \\ {[\mathrm{Mn}]^{*}[\mathrm{Sr}]} & 0.8703032 & 0.487868 & 1.78 & 0.0934 \\ {[\mathrm{Ca}]^{*}[\mathrm{Sr}]} & -1.695352 & 0.487356 & -3.48 & 0.0031 \\ {[\mathrm{Na}]} & -2.062625 & 0.512155 & -4.03 & 0.0010\end{array}$

\section{Model Fit $\left(\mathbf{R}^{2}\right): 0.805364$}

The values shown in Table 7 are the model estimates (coefficients) of the linear response model, the standard errors of the estimates, the statistical $t$ ratio's, and the significance levels. For a parameter to be statistically significant, the significance level should be less than or equal to 0.05 . The resulting model clearly describes the experimentally obtained filterability data well. This fit is evidenced by the residuals square and the fact that all terms are important at the $95 \%$ confidence level with the exception of the linear manganese and strontium terms that have already been discussed. The retention of these parameters is necessitated by higher order terms of sufficient significance for retention that contain that variable of interest as one of the cross terms.

Filterability Extremes

A strategy was developed to find the optimum filterability response for the five variable parameter space examined. The method implemented for this work consisted of several 
steps. The first step was to plot the predicted filterability as a function of the measured filterability. This plot is shown in Figure 3. The actual data points are shown on the graph as well as the $95 \%$ confidence intervals (lines). The experiment number labels on the graph (found in Table 1) correspond to the extreme filterability results. The conditions that correspond to this extreme (highest and lowest) filterability were analyzed for opposing contribution to the extremes.

The data used for next part of the deconvolution strategy are shown in Table 8. By evaluating the conditions associated with the extremes it can be seen that high filterability experiments contained the high level of hydroxide and the low level of calcium. On the other hand, the conditions affiliated with the low filterability extreme are opposite to those of the high extreme. Namely, the level of calcium is high and the level of hydroxide is low for the poor filterability experiments. Once the opposing conditions associated with the extremes were identified the next step in the deconvolution was to hold those two variables constant. The effects of the other three variables were then evaluated.

Figure 3. Predicted vs. Measured Filterability

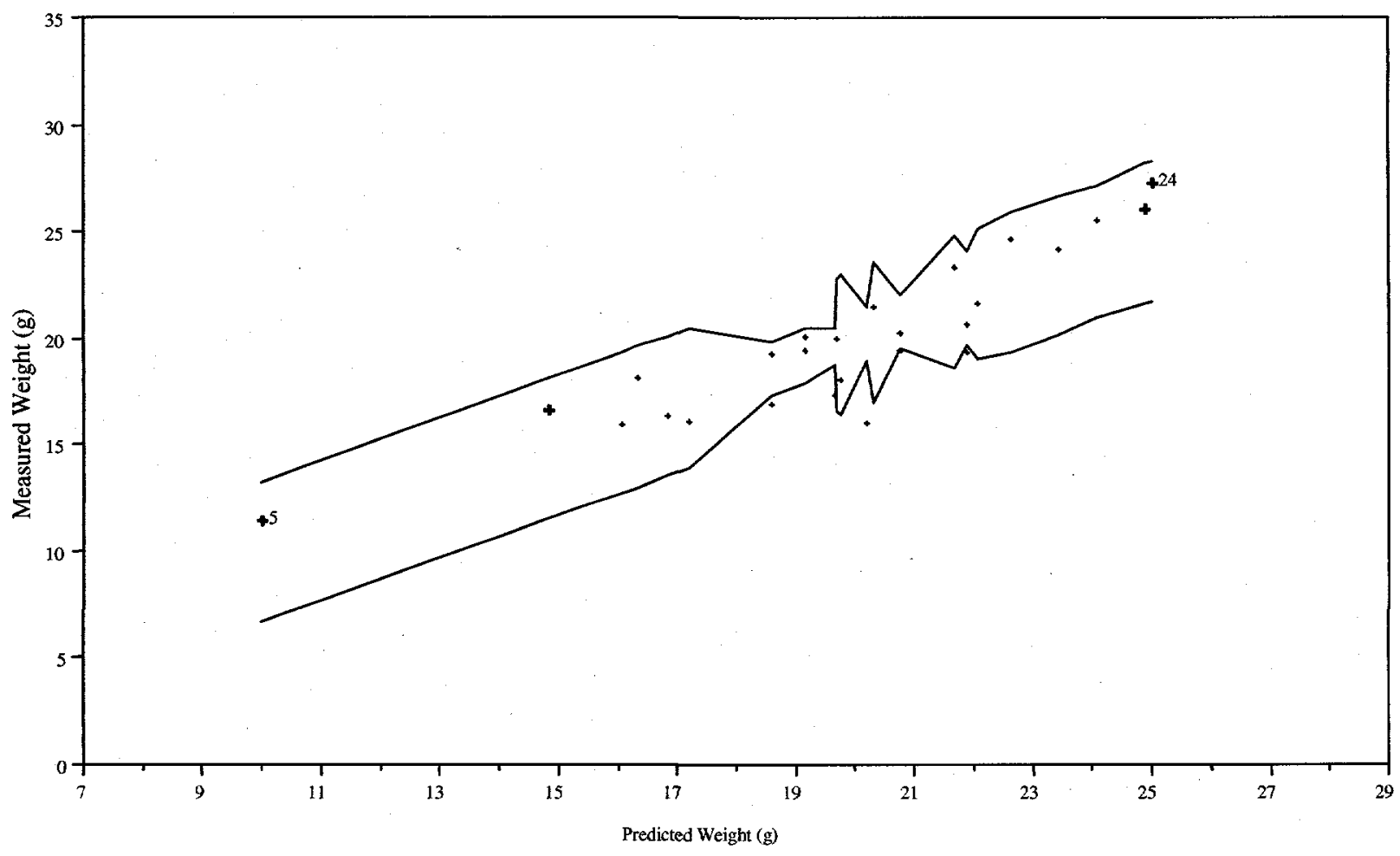


Table 8. Parameter Levels for Extreme Filterability

$\begin{array}{lllccc}\text { Extreme } & {[\mathbf{M n}]} & {[\mathbf{C a}]} & {[\mathbf{O H}]} & {[\mathbf{S r}]} & {[\mathbf{N a}]} \\ \text { Low } & -1 & 1 & -1 & 1 & 1 \\ \text { High } & -1 & -1 & 1 & -1 & -1\end{array}$

Filterability Contour Plots

Based on this evaluation a series of contour plots were constructed to examine the impact of the remaining parameters ( $\mathrm{Sr}, \mathrm{Na}$, and $\mathrm{Mn}$ ) while the levels of calcium and hydroxide were held at the preliminarily determined optimum. These three contour plots are shown in Figures 4-6. Figure 4 reveals that strontium and manganese should both be at the high level or the low level in order to produce the most favorable filterability response. This observation is the direct result of the presence of the [Sr][Mn] cross term in the filterability model. Figure 5 suggests that the sodium level should be low and that the level of strontium selected does not impact the level of sodium chosen. In other words there is no interaction between sodium and strontium. Finally, Figure 6 shows that the selected sodium level is also independent of manganese selection and that again the lowest level of sodium is most favorable.

\section{Figure 4. Contour Plot of Filterability as a Function of Sr and Mn}

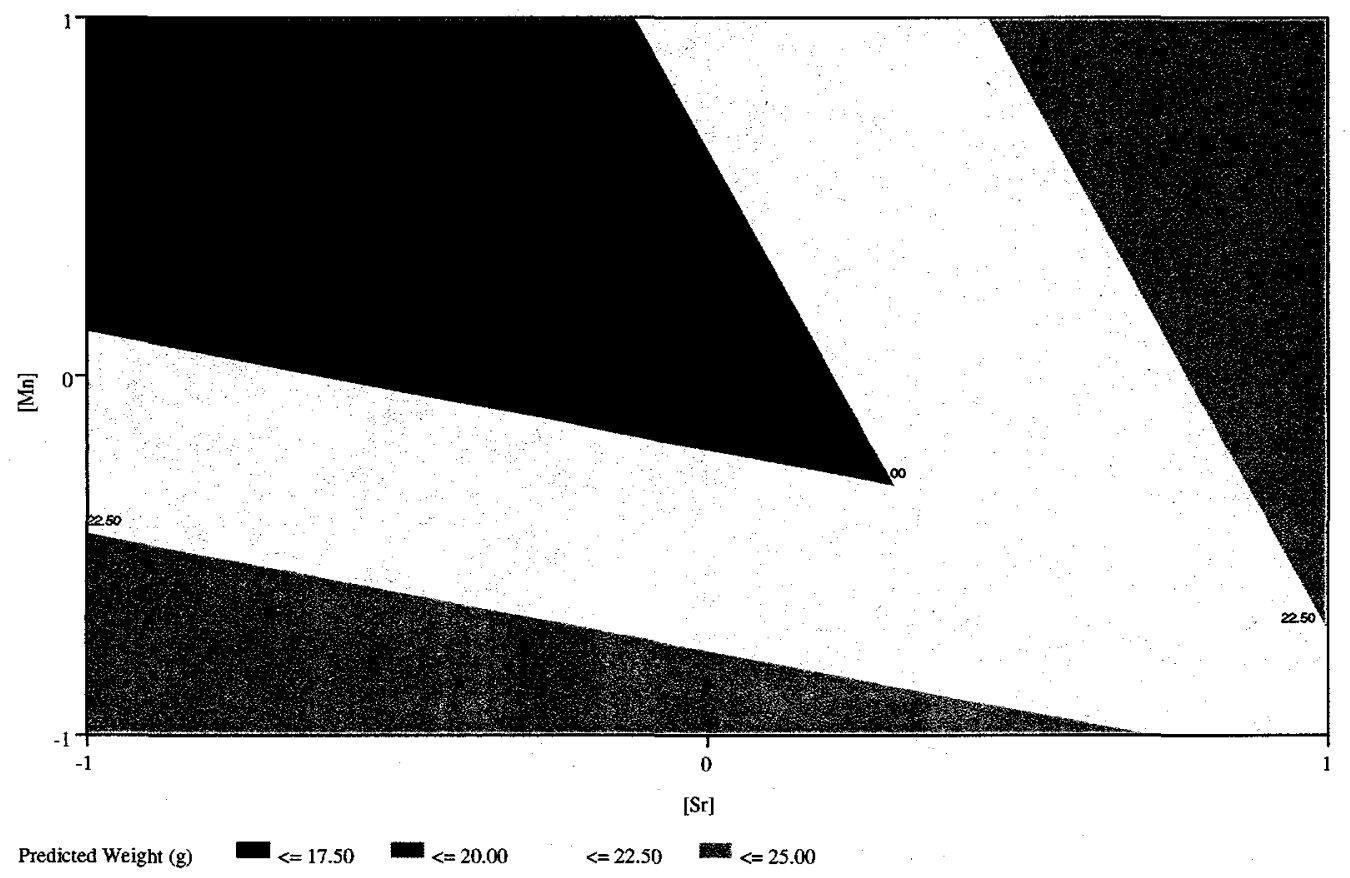


Figure 5. Contour Plot of Filterability as a Function of $\mathrm{Sr}$ and $\mathrm{Na}$

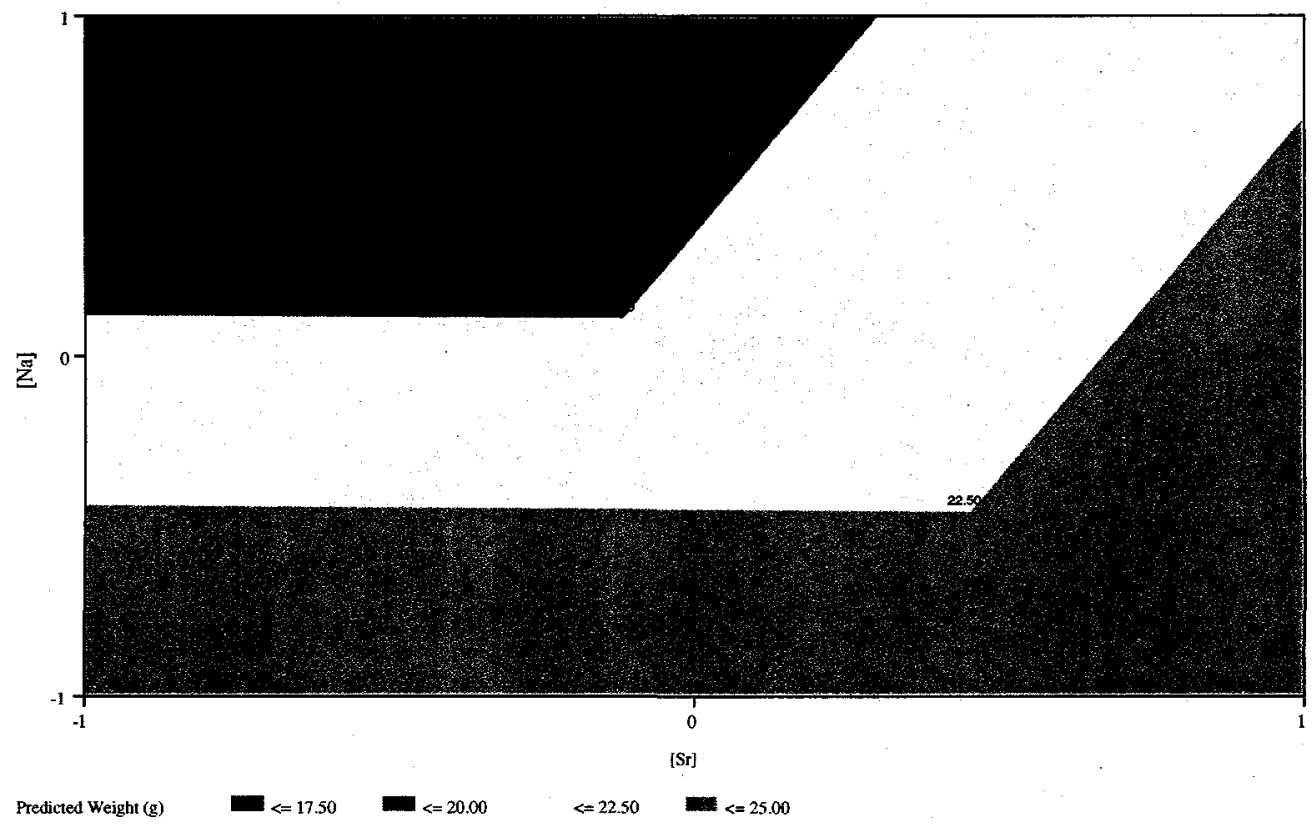

Figure 6. Contour Plot of Filterability as a Function of Mn and Na

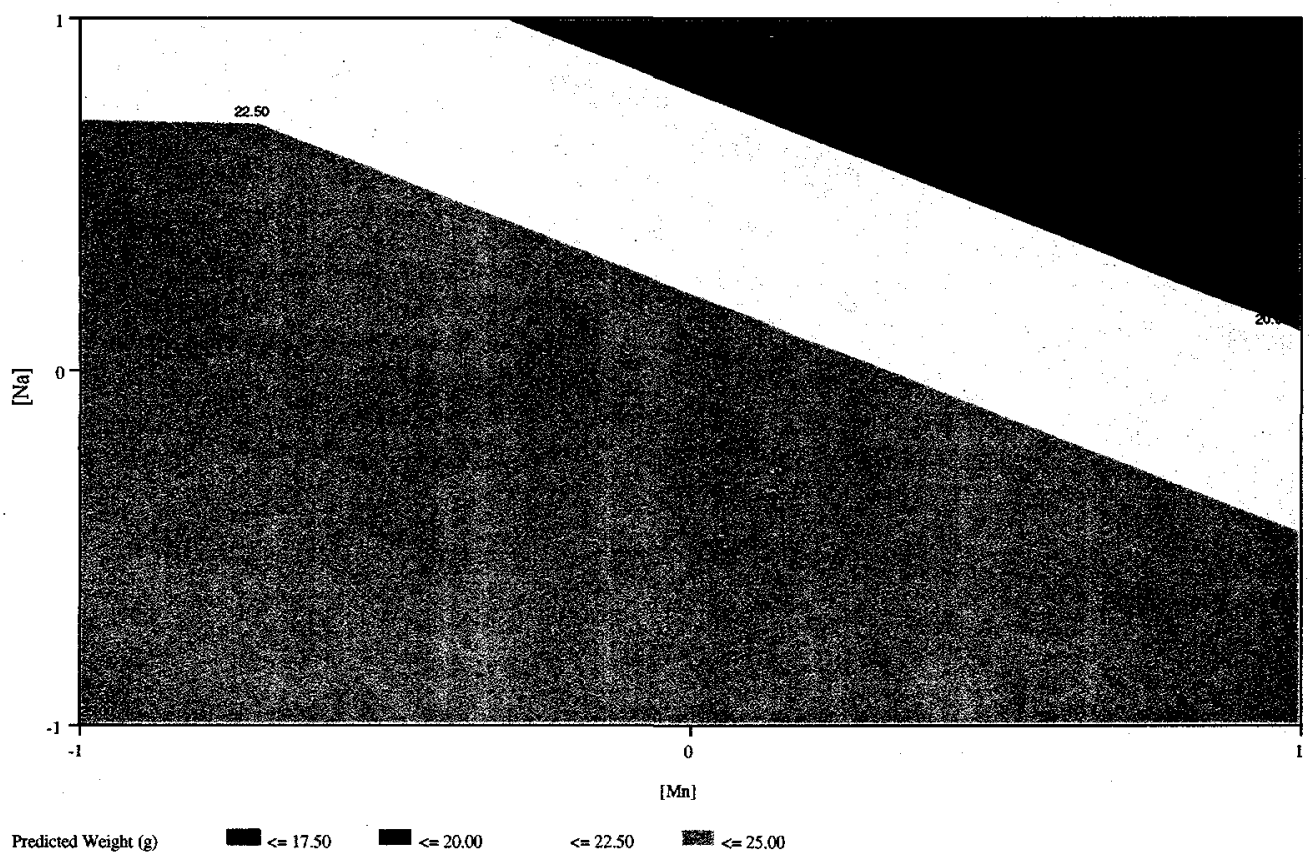


Filterability Optimums

Based on the evaluation of the extremes and consideration of the contour plots a unified story emerges for the optimum conditions for filterability. This interpretation suggests the conditions presented in Table 9 are most beneficial for filterability. More specifically the results suggest that the hydroxide level should be high and the sodium and calcium concentrations should be at the lower level. The most favorable filterability response occurs when strontium and manganese are both introduced at identical bounding values. Namely, either both are high or low.

Table 9. Favorable Conditions for Filterability

\begin{tabular}{cccccc}
\hline & {$[\mathbf{O H}]$} & {$[\mathrm{Na}]$} & {$[\mathbf{C a}]$} & {$[\mathrm{Sr}]$} & {$[\mathrm{Mn}]$} \\
\hline Level & High & Low & Low & Same Extreme as & Same Extreme as \\
& & & & $\mathrm{Mn}$ & $\mathrm{Sr}$ \\
\hline
\end{tabular}

As a means of further evaluating the selected conditions for the optimum a cube plot is presented in Figure 7. This plot consists of a series of four three-dimensional plots. Each of these four plots shows the predicted filterability response at each of the possible combinations of the extremes for the two parameters previously chosen to be fixed. Specifically, the four cubes are for the high $\mathrm{OH}$-high $\mathrm{Ca}$, high $\mathrm{OH}-$ low $\mathrm{Ca}$, low $\mathrm{OH}-$ high $\mathrm{Ca}$, and low $\mathrm{OH}-\mathrm{Low} \mathrm{Ca}$ conditions. The three axes in each cube depict the range for each of the remaining three variables. The filterability response is presented for the five variable conditions described at each corner of each cube. The top number is the filtrate mass in grams expected to be collected in a one minute period through a $5.96 \mathrm{~cm}^{2}$ deadend filter and the bottom number is the volume of filtrate in milliliters expected under the same conditions.

Analysis of the cube plot supports the generalized conclusions gathered from the contour plots. Note that the cube plot shows a very slight sensitivity to the selection of $\mathrm{Sr}$ and Mn. In other words, the face of the high hydroxide-low calcium cube that corresponds to a low value of sodium shows the best filterability response of the entire response surface. The four corners that face of the filterability cube are all among the highest overall and the variation between them as the ratio of strontium and permanganate are changed is negligible. Furthermore, because the model contains no nonlinear terms the analysis can focus on the corners of the cube with a reasonable degree of certainty. 
Figure 7. Cube plots for filterability

$[\mathrm{Ca}]=-1[\mathrm{OH}]=-1$

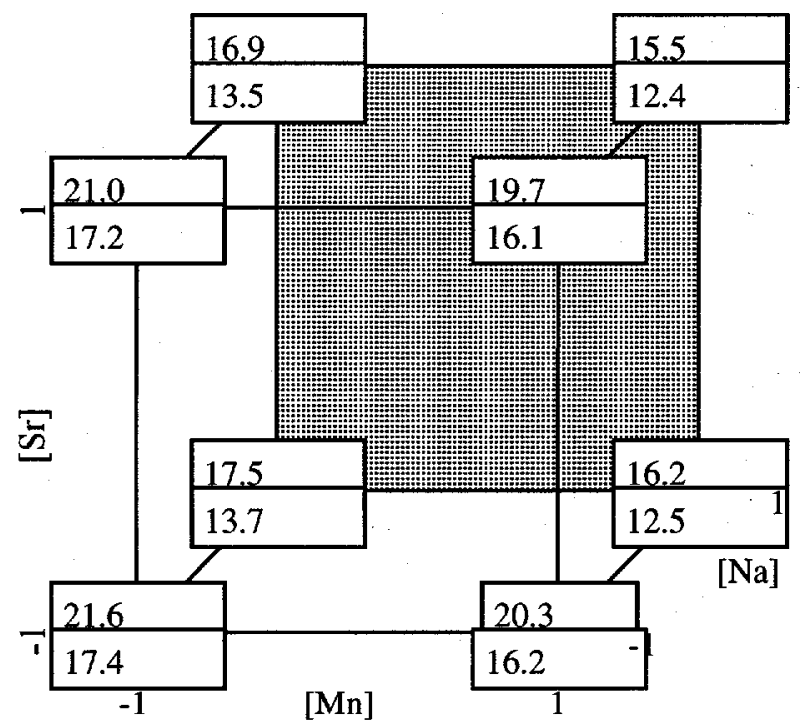

$[\mathrm{Ca}]=-1[\mathrm{OH}]=1$

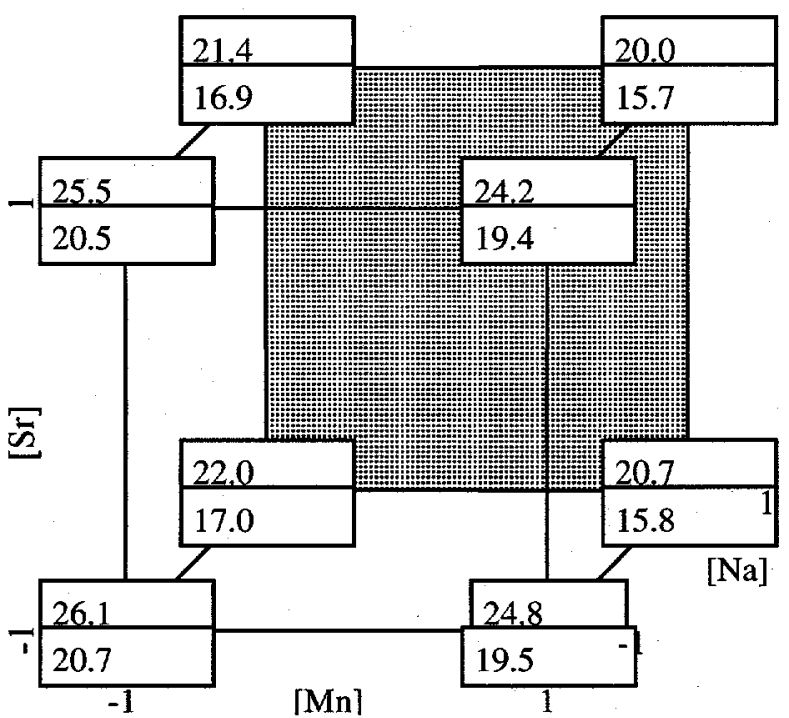

$[\mathrm{Ca}]=1[\mathrm{OH}]=-1$

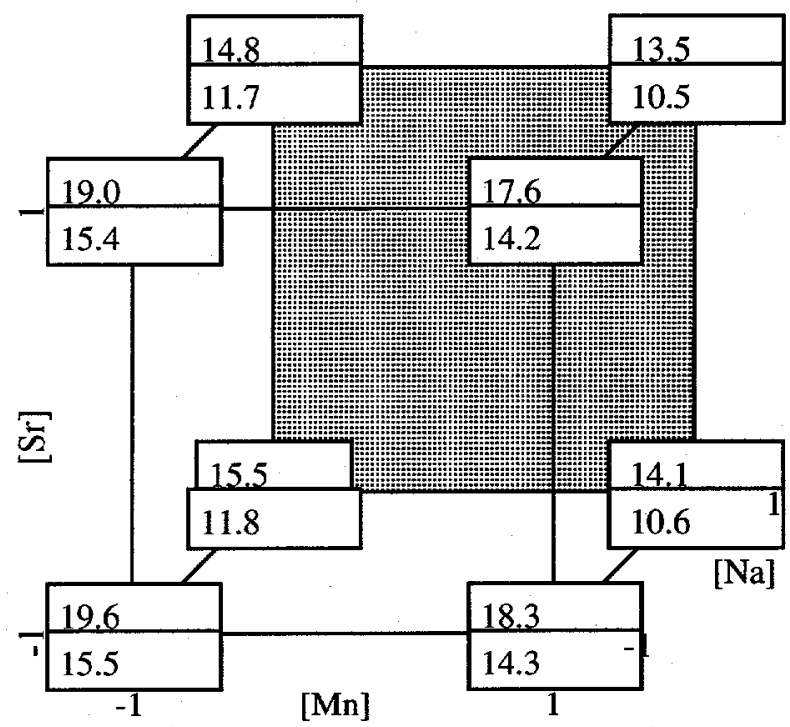

$[\mathrm{Ca}]=1[\mathrm{OH}]=1$

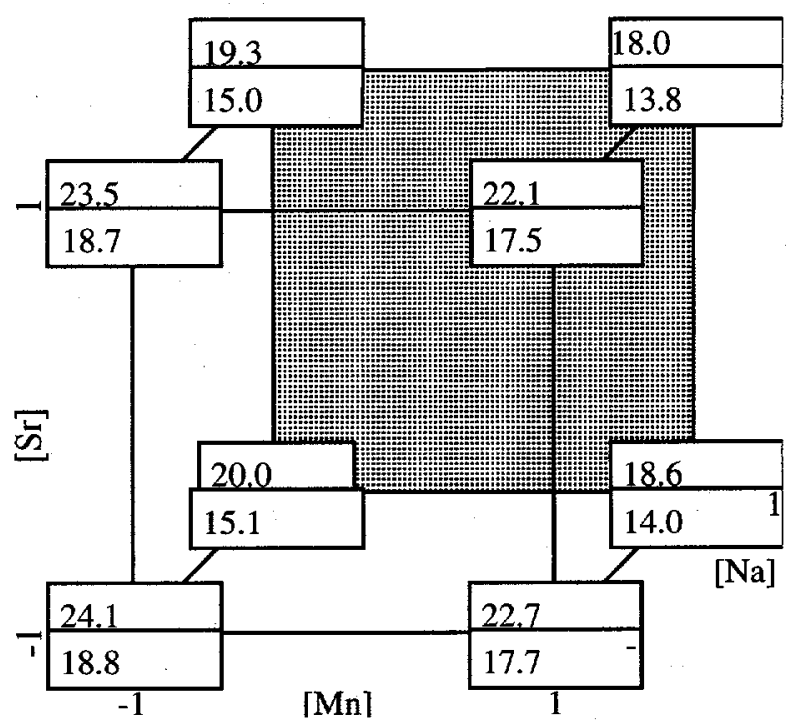




\section{Strontium Decontamination}

\section{Strontium DF Data}

Table 10 contains the strontium-90 decontamination factors determined from the precipitated and sheared $241-\mathrm{AN}-102$ samples. The strontium-90 concentration was measured using Cerenkov counting and/or extaction/scintillation for the initial feeds and the precipitated, sheared and filtered samples. The decontamination factor presented is calculated by simply comparing the ratio of the initial Sr-90 activity to the final activity on a Curie/liter basis. For example if $50 \%$ of the activity were not present relative to the feed the accompanying DF would be two. This calculation does not take into account issues such as dilution involved in various activities such as compositing or precipitating. The worst case scenario in dilution of the final activity affiliated with addition of the precipitants is about $9 \%$.

\section{Strontium DF Modeling}

The Sr-90 decontamination results were used to perform a statistical analysis. The resulting model relating Sr-90 DF of the precipitated slurry to the five precipitation parameters is provided in Table 11. The JMP Statistical program, version 3.2.2 was used to fit the Sr-90 data to a linear function of the five variables. Terms that contributed to the model with less than an $85 \%$ confidence were dropped from the model. This strategy allows only the terms that are most likely contributing to a physical description remain. Some primary terms must remain in the model even though their significance of contribution is much less than the $85 \%$ threshold. The retention of these parameters is necessitated by higher order terms of sufficient significance for retention that contain that variable of interest as one of the cross terms.

The values shown in Table 11 are the model estimates (coefficients) of the linear response model, the standard errors of the estimates, the statistical t ratio's, and the significance levels. For a parameter to be statistically significant, the significance level should be less than or equal to 0.05 . The resulting model clearly describes the experimentally obtained Sr-90 decontamination efficiency data well. This fit is evidenced by the residuals square and the fact that all terms are important at the $95 \%$ confidence level with the exception of the primary manganese term which is retained for the previously discussed reason.

\section{Strontium DF Extremes}

A strategy was developed to find the optimum Sr-90 DF response for the five variable parameter space examined. The method implemented for this evaluation consisted of several steps. The first was to plot the predicted decontamination as a function of the measured decontamination. These data points are shown in Figure 8 as well as the associated $95 \%$ confidence intervals (lines). The design numbers from Table 1 which correspond to the extremes are shown on the graph. The conditions afiliated with these 
extreme (highest and lowest) Sr-90 decontaminations were analyzed for opposing contribution to the observed decontamination effeciency.

Table 10. Calculated Strontium-90 Decontamination Factors

\begin{tabular}{lcc} 
& & \\
SAMPLE ID & Sr-DF & + - for $95 \%$ conf. \\
BNFL-15B-EXP-1-B1 & 53.0 & 10.5 \\
BNFL-15B-EXP-2-B1 & 3.2 & 0.6 \\
BNFL-15B-EXP-3-B1 & 13.6 & 2.7 \\
BNFL-15B-EXP-4-B1 & 6.4 & 1.3 \\
BNFL-15B-EXP-5-B1 & 46.2 & 9.2 \\
BNFL-15B-EXP-6-B1 & 41.1 & 8.1 \\
BNFL-15B-EXP-7-B1 & 29.0 & 5.7 \\
BNFL-15B-EXP-8-B1 & 15.6 & 3.1 \\
BNFL-15B-EXP-9-B1 & 32.2 & 6.4 \\
BNFL-15B-EXP-10-B1 & 37.0 & 7.3 \\
BNFL-15B-EXP-11-B1 & 33.6 & 6.7 \\
BNFL-15B-EXP-12-B1 & 59.3 & 11.7 \\
BNFL-15B-EXP-14-B1 & 81.4 & 16.1 \\
BNFL-15B-EXP-15-B1 & 35.2 & 7.0 \\
BNFL-15B-EXP-16-B1 & 38.9 & 7.7 \\
BNFL-15B-EXP-17-B1 & 15.0 & 3.0 \\
BNFL-15B-EXP-18-B1 & 9.9 & 2.0 \\
BNFL-15B-EXP-19-B1 & 16.0 & 3.2 \\
BNFL-15B-EXP-20-B1 & 65.0 & 12.9 \\
BNFL-15B-EXP-21-B1 & 41.0 & 8.1 \\
BNFL-15B-EXP-22-B1 & - & - \\
BNFL-15B-EXP-23-B1 & 55.2 & 10.9 \\
BNFL-15B-EXP-24-B1 & 14.9 & 3.0 \\
BNFL-15B-EXP-26-B1 & 23.1 & 4.6 \\
BNFL-15B-EXP-14F5-B1 & 74.5 & 14.8 \\
BNFL-15B-EXP-18F1-B1 & 7.0 & 1.4 \\
BNFL-15B-EXP-27F4-B1 & 87.0 & 17.2 \\
BNFL-15B-EXP-13R-B1 & 11.0 & 2.2 \\
BNFL-15B-EXP-4R-B11 & 17.0 & 3.4 \\
& & \\
\hline & & \\
B 10 &
\end{tabular}


Table 11. Statistical Analysis Results for Sr-90 DF

$\begin{array}{lrrrr}\text { Term } & \text { Estimate } & \text { Std Error } & t \text { Ratio } & \text { Prob }>|\mathbf{t}| \\ \text { Intercept } & 20.158595 & 5.532757 & 3.64 & 0.0022 \\ {[\mathrm{Mn}]} & -0.32781 & 2.005027 & -0.16 & 0.8722 \\ {[\mathrm{Ca}]} & -3.798486 & 1.996236 & -1.90 & 0.0752 \\ {[\mathrm{Sr}]} & 21.491097 & 2.189492 & 9.82 & <.0001 \\ {[\mathrm{Mn}]^{*}[\mathrm{Sr}]} & -4.428597 & 2.189492 & -2.02 & 0.0602 \\ {[\mathrm{Na}]} & -5.52462 & 2.312316 & -2.39 & 0.0295 \\ {[\mathrm{Ca}]^{*}[\mathrm{Na}]} & 2.9128801 & 2.312316 & 1.26 & 0.2258 \\ {[\mathrm{Mn}]^{*}[\mathrm{Mn}]} & 10.89781 & 4.42169 & 2.46 & 0.0254 \\ {\left[\mathrm{Ca}{ }^{*}[\mathrm{Ca}]\right.} & 7.076756 & 4.854153 & 1.46 & 0.1642\end{array}$

Model Fit $\left(\mathrm{R}^{2}\right): 0.89$

Figure 8. Predicted vs. Measured Sr-90 Decontamination Factors

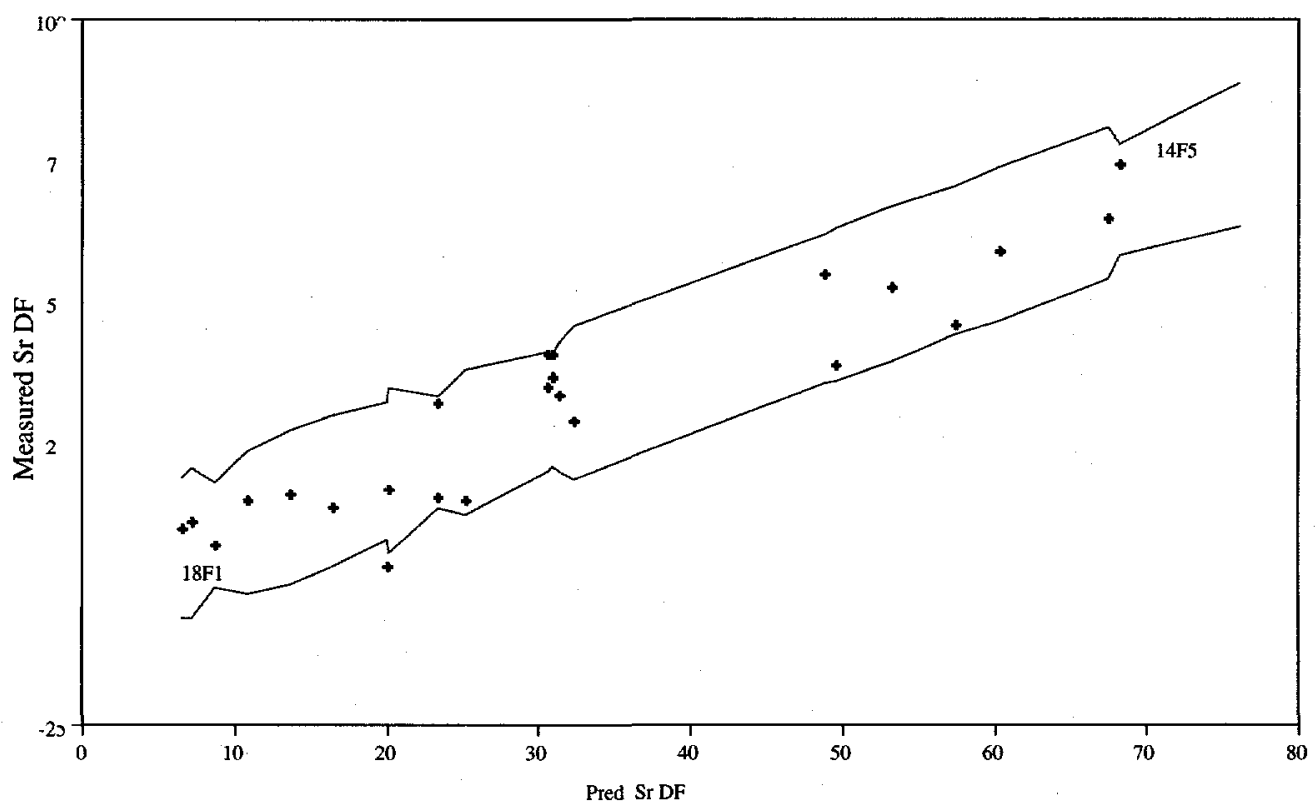

The data used for the next step in the deconvolution are shown in Table 12. By evaluating the conditions associated with the extremes it can be seen that the experimental conditions which yield the highest Sr-90 DF contained the low levels of hydroxide and calcium. On the other hand, the values for these two parameters during the low filterability extreme are opposite to those of the high extreme. Namely, the levels 
of calcium and hydroxide are high for the poor Sr-90 DF experiment. Once the opposing conditions associated with the extremes were identified the next step in the analysis was to hold these two variables constant. The effects of the other three variables were then evaluated.

\section{Table 12. Parameter Levels for Extreme Sr-90 DF}

$\begin{array}{llllll}\text { Extreme DF } & {[\mathbf{M n}]} & {[\mathbf{C a}]} & {[\mathbf{O H}]} & {[\mathbf{S r}]} & {[\mathbf{N a}]} \\ \text { Low } & -1 & 1 & 1 & -1 & 1 \\ \text { High } & -1 & -1 & -1 & 1 & -1\end{array}$

\section{Strontium DF Contour Plots}

Based on this evaluation a series of contour plots were constructed to examine the impact of the remaining parameters ( $\mathrm{Sr}, \mathrm{Na}$, and $\mathrm{Mn}$ ) while the levels of calcium and hydroxide were held at the preliminarily determined optimum. These three contour plots are shown in Figures 9-11. Figure 9 reveals that the most favorable levels are high for strontium and low for manganese to facilitate the best Sr-90 decontamination. Figure 10 suggests that the sodium level should be low and that the level of strontium should be high as already concluded from the previous figure. Finally, Figure 11 shows that the levels for sodium and manganese addition that are most favorable for Sr-90 DF are low.

Figure 9. Contour Plot of Sr-90 DF as a Function of Sr and Mn

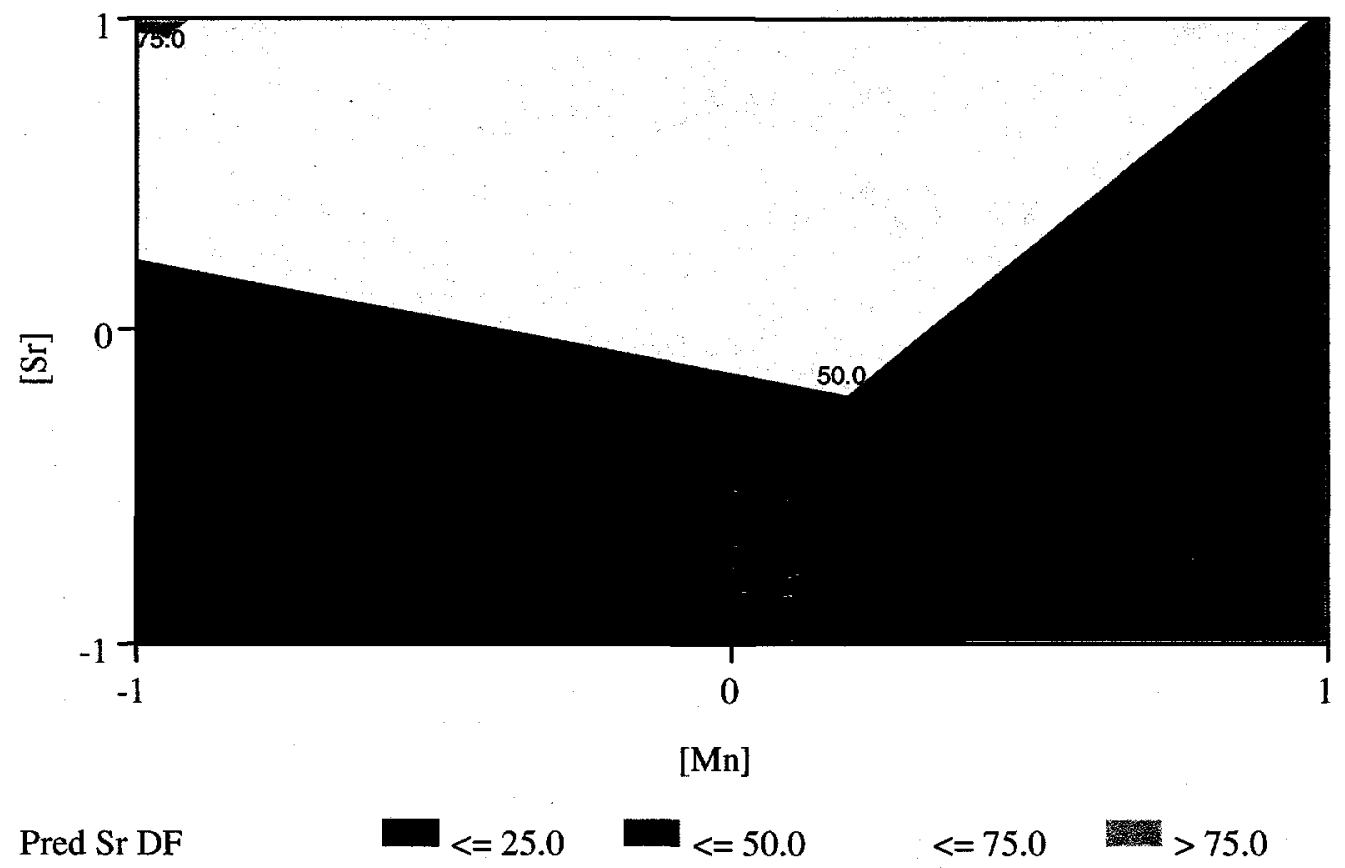


Figure 10. Contour Plot of Sr-90 DF as a Function of Sr and Na

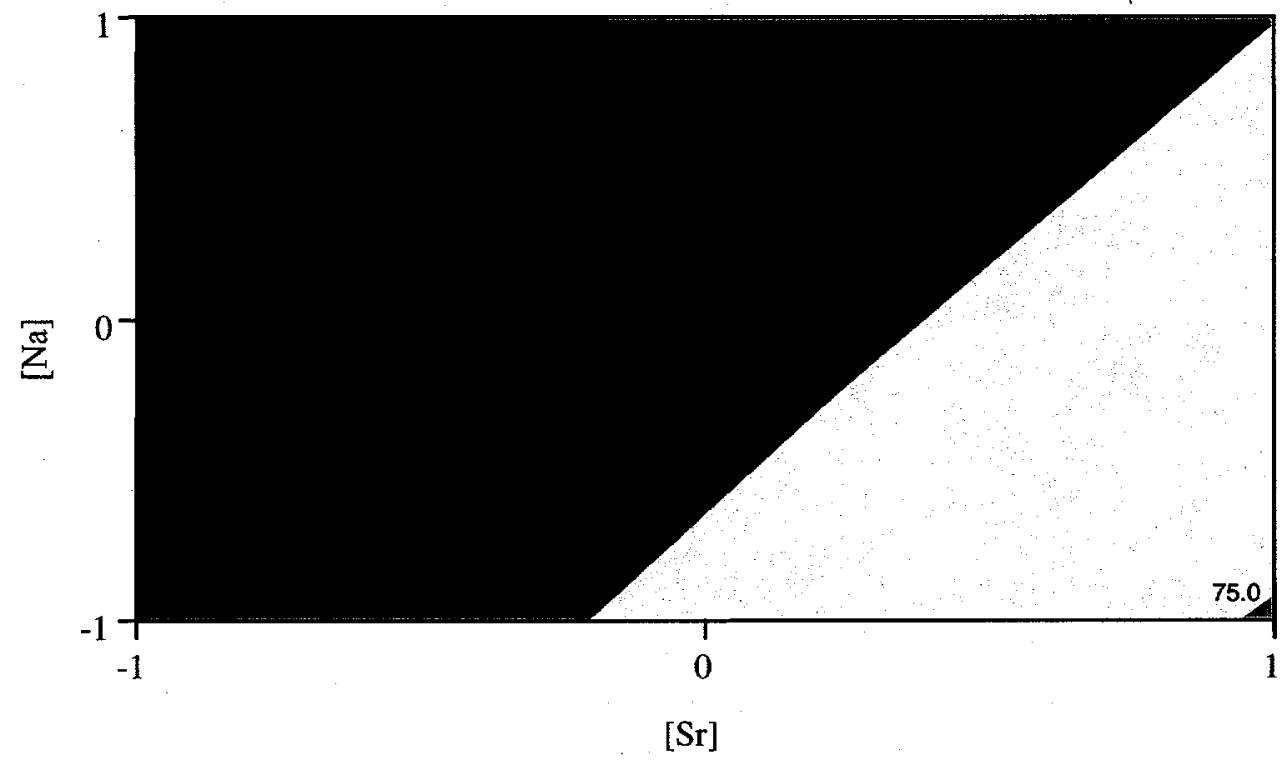

Pred Sr DF $<=25.0$ $<=75.0$

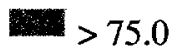

Figure 11. Contour Plot of Sr-90 DF as a Function of Na and Mn

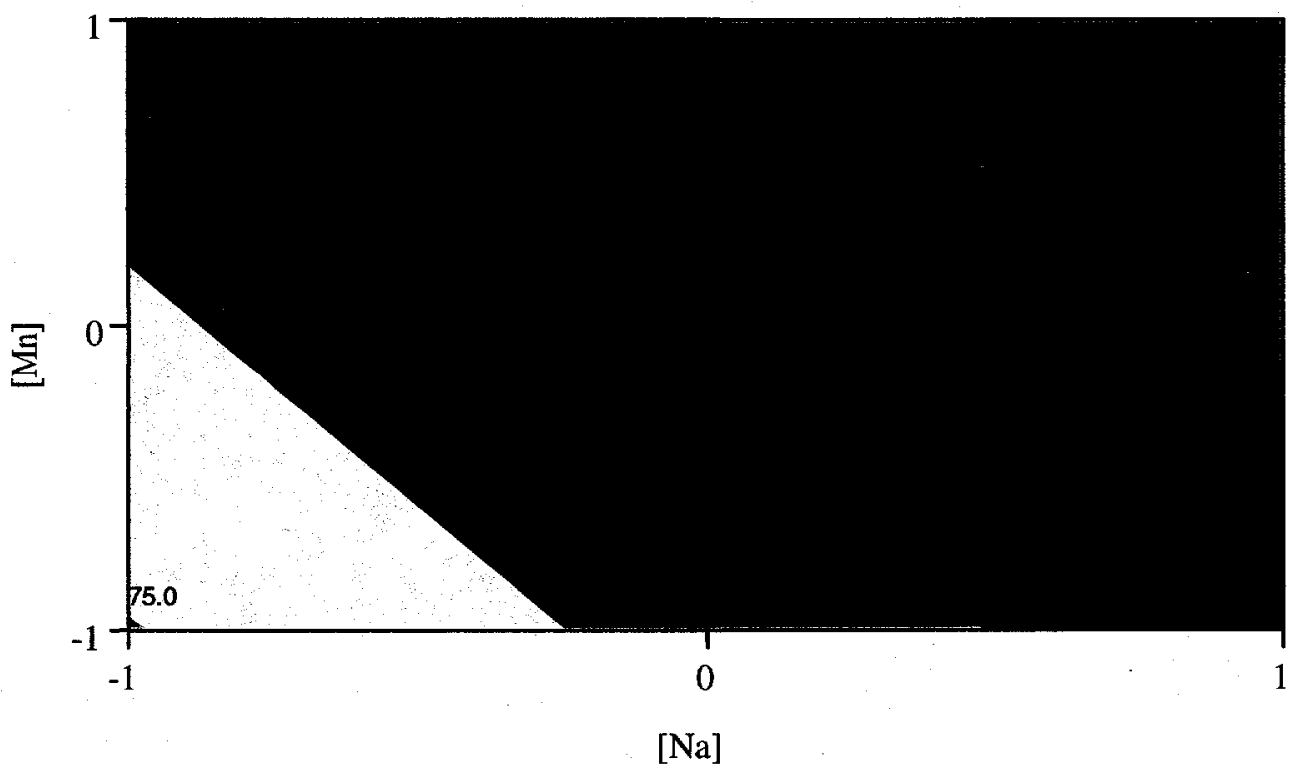

Pred Sr DF

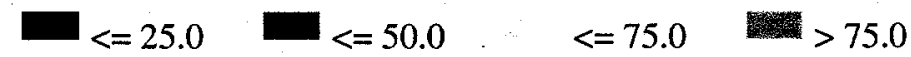




\section{Strontium DF Optimums}

Based on the evaluation of the extremes and consideration of the contour plots a unified story emerges for the optimum conditions for Sr-90 DF. This interpretation suggests the conditions presented in Table 13 are most beneficial for decontamination of strontium. More specifically the results suggest that the strontium level should be high and the sodium, calcium, and manganese concentrations should be at their low levels. Hydroxide does not enter into the model and can be any value.

Table 13. Favorable Conditions for $\mathrm{Sr}-90 \mathrm{DF}$

\begin{tabular}{cccccc}
\hline & {$[\mathrm{OH}]$} & {$[\mathrm{Na}]$} & {$[\mathrm{Ca}]$} & {$[\mathrm{Sr}]$} & {$[\mathrm{Mn}]$} \\
\hline Level & Any Value & Low & Low & High & Low \\
\hline
\end{tabular}

As a mean of cross checking the selected conditions for the optimum a cube plot is presented in Figure 12. This plot consists of a series of four three-dimensional plots. Each of these four plots shows the predicted Sr-90 DF response at each of the possible combinations of the extremes for the two parameters previously chosen to be fixed.

Specifically, the four cubes are for the high $\mathrm{OH}$-high $\mathrm{Ca}$, high $\mathrm{OH}$-low $\mathrm{Ca}$, low $\mathrm{OH}$-high $\mathrm{Ca}$, and low $\mathrm{OH}$-Low $\mathrm{Ca}$ conditions. The three axes in each cube depict the range for each of the remaining three variables. The predicted $\mathrm{Sr}-90 \mathrm{DF}$ response is presented for the five variable conditions described at each corner of the four cubes. Analysis of the cube plot supports the generalized conclusions. In other words, the intersection of the high hydroxide-low calcium cube which corresponds to the low value of sodium, low value of manganese, and high value of strontium is predicted to be the best Sr-90 DF for the entire response surface. 
Figure 12. Cube Plots for Sr-90 DF

$[\mathrm{Ca}]=-1[\mathrm{OH}]=-1$

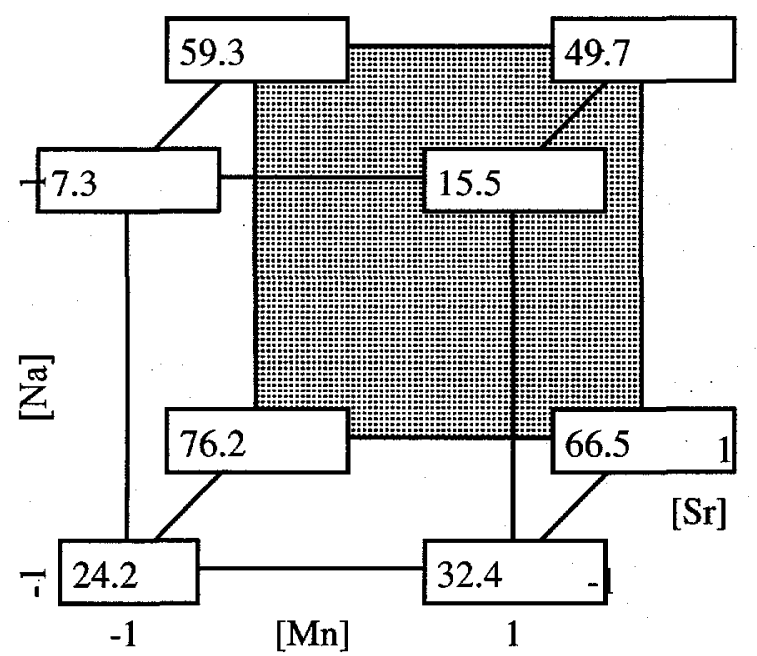

$[\mathrm{Ca}]=-1[\mathrm{OH}]=1$

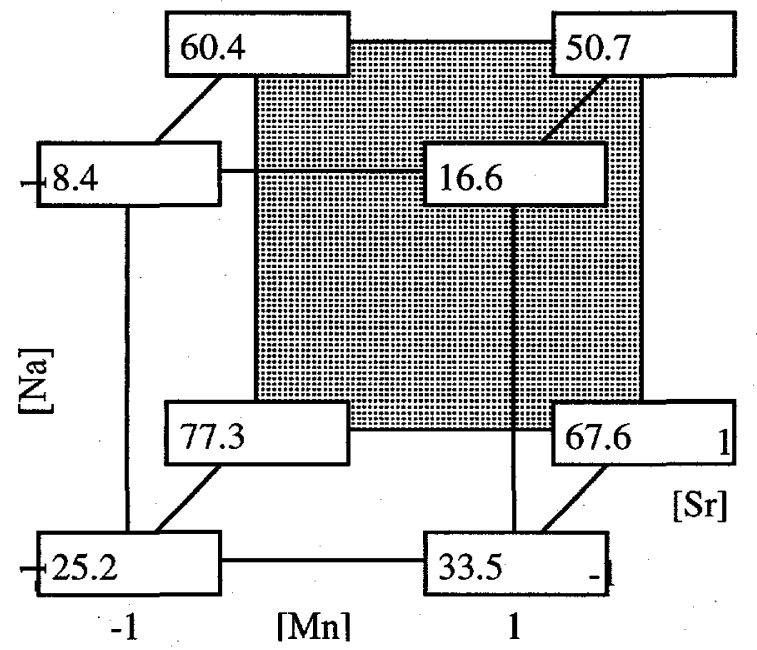

$[\mathrm{Ca}]=1[\mathrm{OH}]=-1$

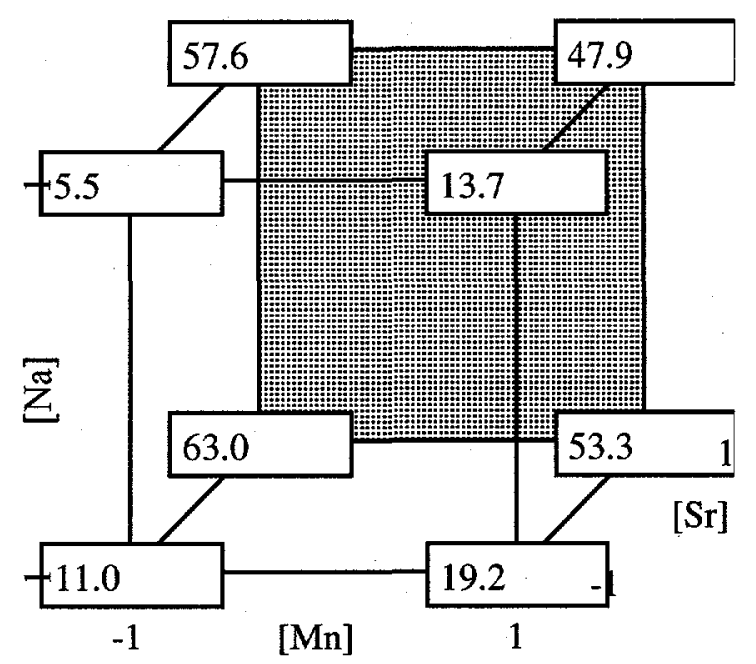

$[\mathrm{Ca}]=1[\mathrm{OH}]=1$

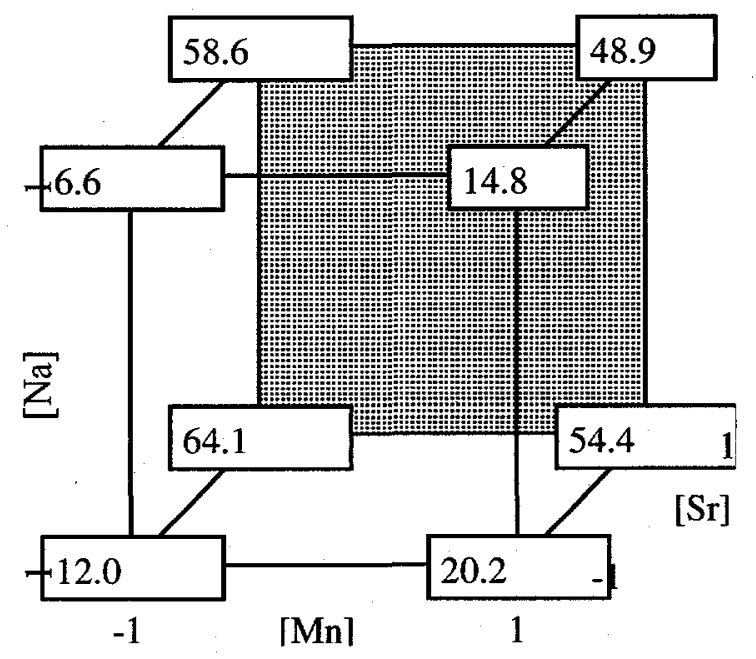




\section{$\underline{\text { Plutonium Decontamination }}$}

\section{Plutonium DF Data}

Table 14 contains the plutonium decontamination factors determined from the precipitated and sheared 241-AN-102 samples. The plutonium concentration was measured using alpha-PHA counting for the initial feeds and the precipitated, sheared and filtered samples. The plutonium value used to calculate the decontamination factor was for the total of isotopes 238,239 , and 240 . The decontamination factor presented is calculated by simply comparing the ratio of this total plutonium activity to the activity in the final sample after pretreatment. For example if 50\% of the activity were not present relative to the feed the accompanying DF would be two. This calculation does not take into account issues such as dilution involved in various activities such as compositing or precipitating. The worst case scenario in dilution of the final activity affiliated with addition of the precipitants is about $9 \%$.

\section{Plutonium DF Modeling}

The Pu decontamination results were used to perform a statistical analysis. The resulting model relating this DF of the precipitated slurry to the five precipitation parameters is provided in Table 15. The JMP Statistical program, version 3.2.2 was used to fit the data to a linear function of the five variables. Terms that contributed to the model with less than an $85 \%$ confidence were dropped from the model. This strategy allows only the terms that are most likely contributing to a physical description remain. Some primary terms must remain in the model even though their significance of contribution is much less than the $85 \%$ threshold. This retention of these parameters is necessitated by higher order terms of sufficient significance for retention that contain that variable of interest as one of the cross terms.

The values shown in Table 15 are the model estimates (coefficients) of the linear response model, the standard errors of the estimates, the statistical t ratio's, and the significance levels. For a parameter to be statistically significant, the significance level should be less than or equal to 0.05 . The resulting model clearly describes the experimentally obtained total plutonium removal efficiency data well. This fit is evidenced by the residuals square and the fact that all terms are important at the $95 \%$ confidence level with the exception of the primary sodium term which is retained for the previously discussed reason.

\section{Plutonium DF Extremes}

A strategy was developed to find the optimum $\mathrm{Pu}$ DF response for the five variable parameter space examined. The method implemented for this evaluation consisted of several steps. The first was to plot the predicted decontamination as a function of the measured decontamination. These data points are shown in Figure 13 as well as the associated $95 \%$ confidence intervals (lines). The design numbers from Table 1 which 
correspond to the extremes are shown on the graph. The conditions afiliated with these extreme (highest and lowest) Pu decontaminations were analyzed for opposing contribution to the observed decontamination effeciency.

Table 14. Calculated Total Plutonium Decontamination Factors

\begin{tabular}{|c|c|c|}
\hline SAMPLE ID & Pu-total-DF & $+/-$ for $95 \%$ conf. \\
\hline BNFL-15B-EXP-1-B1 & 2.7 & 0.7 \\
\hline BNFL-15B-EXP-2-B1 & 2.0 & 0.6 \\
\hline BNFL-15B-EXP-3-B1 & 2.0 & 0.5 \\
\hline BNFL-15B-EXP-4-B1 & 0.9 & 0.2 \\
\hline BNFL-15B-EXP-5-B1 & 2.4 & 0.6 \\
\hline BNFL-15B-EXP-6-B1 & 2.1 & 0.6 \\
\hline BNFL-15B-EXP-7-B1 & 1.5 & 0.4 \\
\hline BNFL-15B-EXP-8-B1 & 2.5 & 0.7 \\
\hline BNFL-15B-EXP-9-B1 & 2.2 & 0.6 \\
\hline BNFL-15B-EXP-10-B1 & 1.7 & 0.5 \\
\hline BNFL-15B-EXP-11-B1 & 1.6 & 0.4 \\
\hline BNFL-15B-EXP-12-B1 & 1.0 & 0.3 \\
\hline BNFL-15B-EXP-14-B1 & 2.3 & 0.6 \\
\hline BNFL-15B-EXP-15-B1 & 2.2 & 0.6 \\
\hline BNFL-15B-EXP-16-B1 & 2.1 & 0.6 \\
\hline BNFL-15B-EXP-17-B1 & 1.6 & 0.4 \\
\hline BNFL-15B-EXP-18-B1 & 0.5 & 0.1 \\
\hline BNFL-15B-EXP-19-B1 & 1.8 & 0.5 \\
\hline BNFL-15B-EXP-20-B1 & 2.1 & 0.6 \\
\hline BNFL-15B-EXP-21-B1 & 2.2 & 0.6 \\
\hline BNFL-15B-EXP-22-B1 & 2.5 & 0.7 \\
\hline BNFL-15B-EXP-23-B1 & 1.8 & 0.5 \\
\hline BNFL-15B-EXP-24-B1 & 1.9 & 0.5 \\
\hline BNFL-15B-EXP-26-B1 & 1.8 & 0.5 \\
\hline BNFL-15B-EXP-14F5-B1 & 1.6 & 0.4 \\
\hline BNFL-15B-EXP-18F1-B1 & 1.6 & 0.4 \\
\hline BNFL-15B-EXP-27F4-B1 & 2.0 & 0.5 \\
\hline BNFL-15B-EXP-13R-B1 & 1.9 & 0.5 \\
\hline BNFL-15B-EXP-4R-B1 & 2.5 & 0.7 \\
\hline
\end{tabular}


Table 15. Statistical Analysis Results for Total Pu DF

$\begin{array}{lrrrr}\text { Term } & \text { Estimate } & \text { Std Error } & \text { t Ratio } & \text { Prob }>|\mathbf{t}| \\ \text { Intercept } & 1.9547456 & 0.046455 & 42.08 & <.0001 \\ {[\mathrm{Mn}]} & 0.171568 & 0.051744 & 3.32 & 0.0047 \\ {[\mathrm{Ca}]} & 0.1035714 & 0.050513 & 2.05 & 0.0582 \\ {[\mathrm{OH}]} & -0.125 & 0.058932 & -2.12 & 0.0510 \\ {[\mathrm{Sr}]} & 0.1892857 & 0.055845 & 3.39 & 0.0040 \\ {[\mathrm{Na}]} & -0.225 & 0.058932 & -3.82 & 0.0017 \\ {[\mathrm{OH}]^{*}[\mathrm{Mn}]} & 0.1625 & 0.058932 & 2.76 & 0.0147 \\ {[\mathrm{Sr}]^{*}[\mathrm{Ca}]} & 0.1759086 & 0.056079 & 3.14 & 0.0068 \\ {[\mathrm{Sr}]^{*}[\mathrm{OH}]} & -0.1375 & 0.058932 & -2.33 & 0.0340 \\ {[\mathrm{Na}]^{*}[\mathrm{Ca}]} & -0.125 & 0.058932 & -2.12 & 0.0510 \\ {[\mathrm{Na}]^{*}[\mathrm{OH}]} & -0.2375 & 0.058932 & -4.03 & 0.0011\end{array}$

Model Fit $\left(\mathrm{R}^{2}\right): 0.857732$

Figure 13. Predicted vs. Measured Pu Decontamination Factors

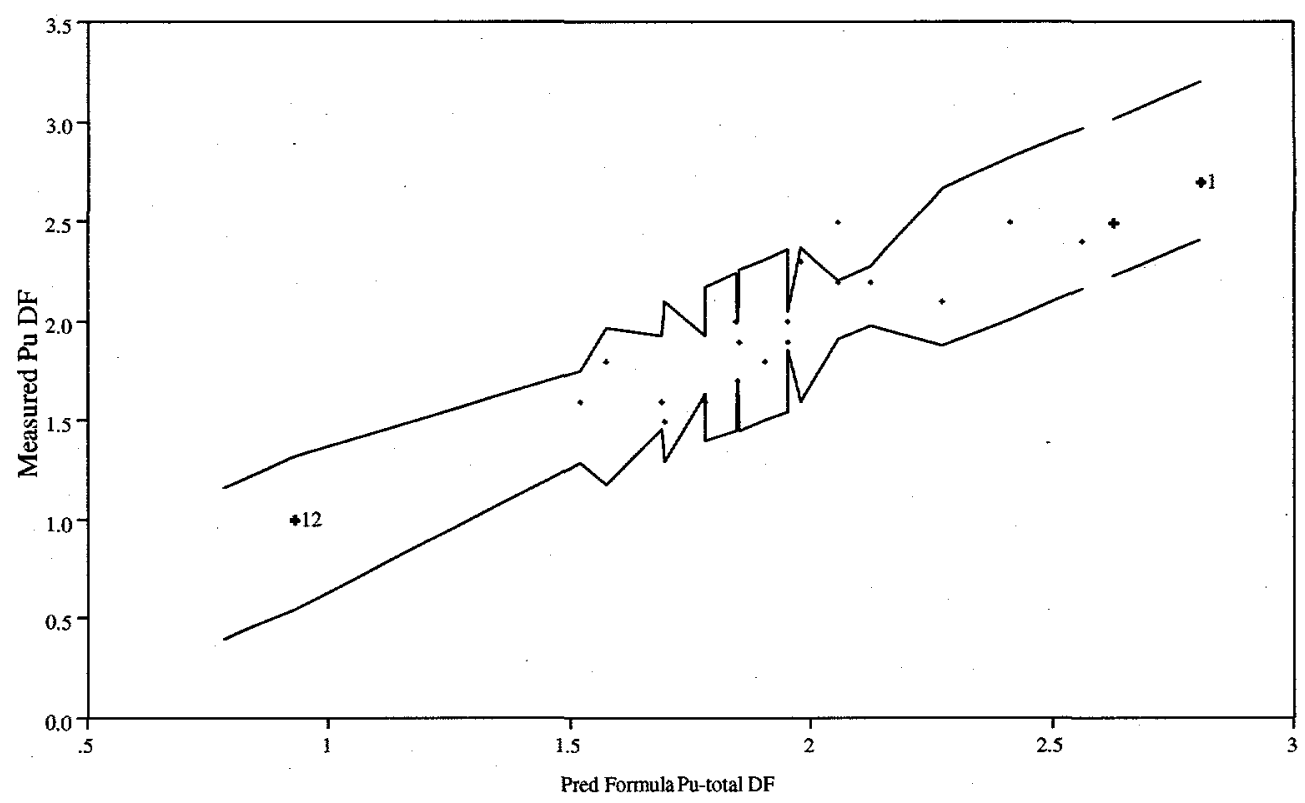

The data used for the next step in the analysis of plutonium decontamination are shown in Table 16. By evaluating the conditions associated with the extremes it can be seen that the experimental conditions which yield the highest DF contained the low level of sodium and the high level of manganese. On the other hand, the conditions affiliated 
with the low filterability extreme are opposite to those of the high extreme. Namely, the level of manganese is low and the level of sodium is high for the poor Pu DF extreme. Once the opposing conditions associated with the extremes were identified these two variables were held constant and the effects of the other three variables were evaluated.

Table 16. Parameter Levels for Extreme Pu DF

Extreme DF
Low
High

[Mn]
-1
1

[Ca]
-1
1
[OH] 1 $-1$
[Sr] 1
1
[Na] 1 $-1$

\section{Plutonium DF Contour Plots}

Based on this evaluation a series of contour plots were constructed to examine the impact of the remaining parameters $(\mathrm{Sr}, \mathrm{OH}$, and $\mathrm{Ca}$ ) while the levels of sodium and manganese were held at the preliminarily determined optimum. These three contour plots are shown in Figures 14-16. Figure 14 reveals that the most favorable levels are high for calcium and low for hydroxide to facilitate the best decontamination. Figure 15 suggests that the hydroxide level should be low, in agreement with Figure 14, and the level of strontium should be high. Finally, Figure 16 shows that the levels for strontium and calcium addition that are most favorable for DF are high. This observation is in agreement with the preceding conclusions.

Figure 14. Contour Plot of Pu DF as a Function of $\mathrm{Ca}$ and $\mathrm{OH}$

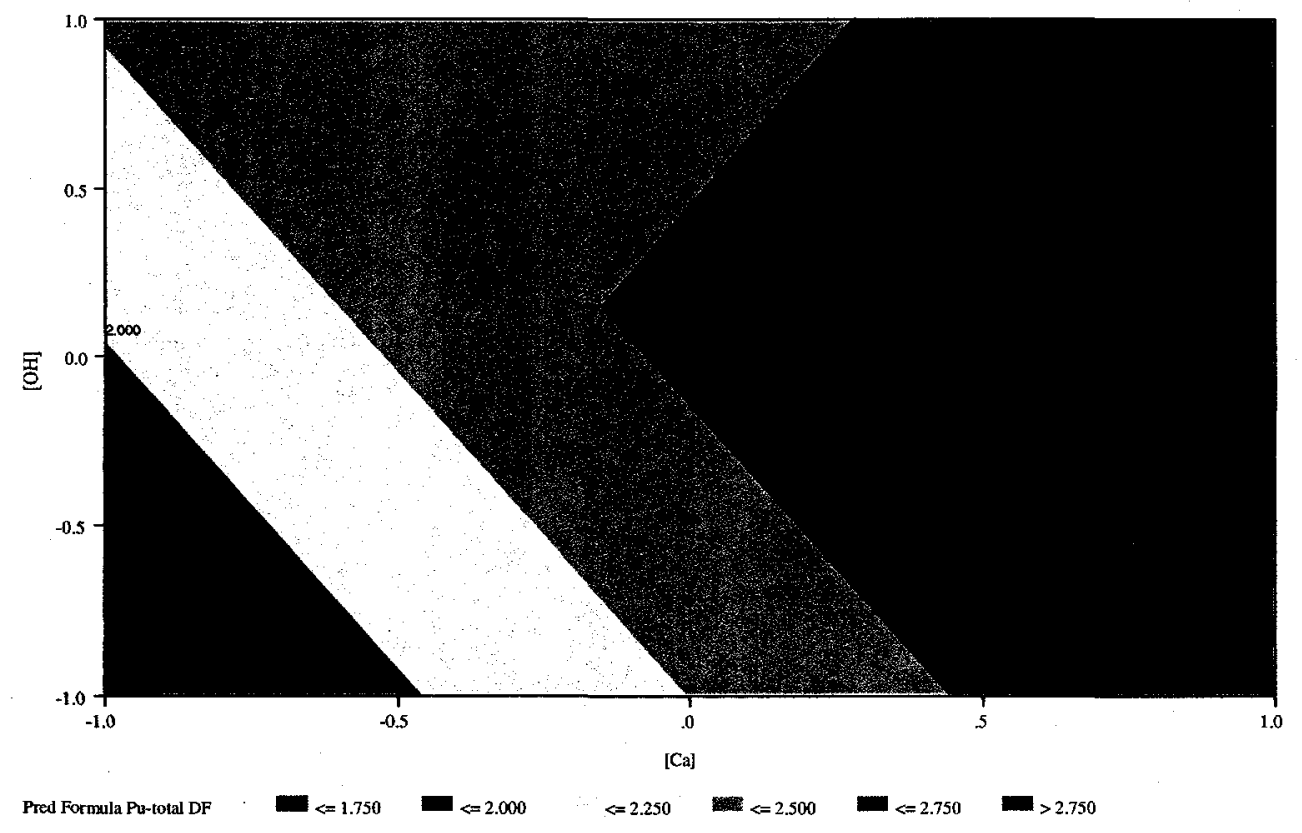


Figure 15. Contour Plot of Pu DF as a Function of Sr and OH

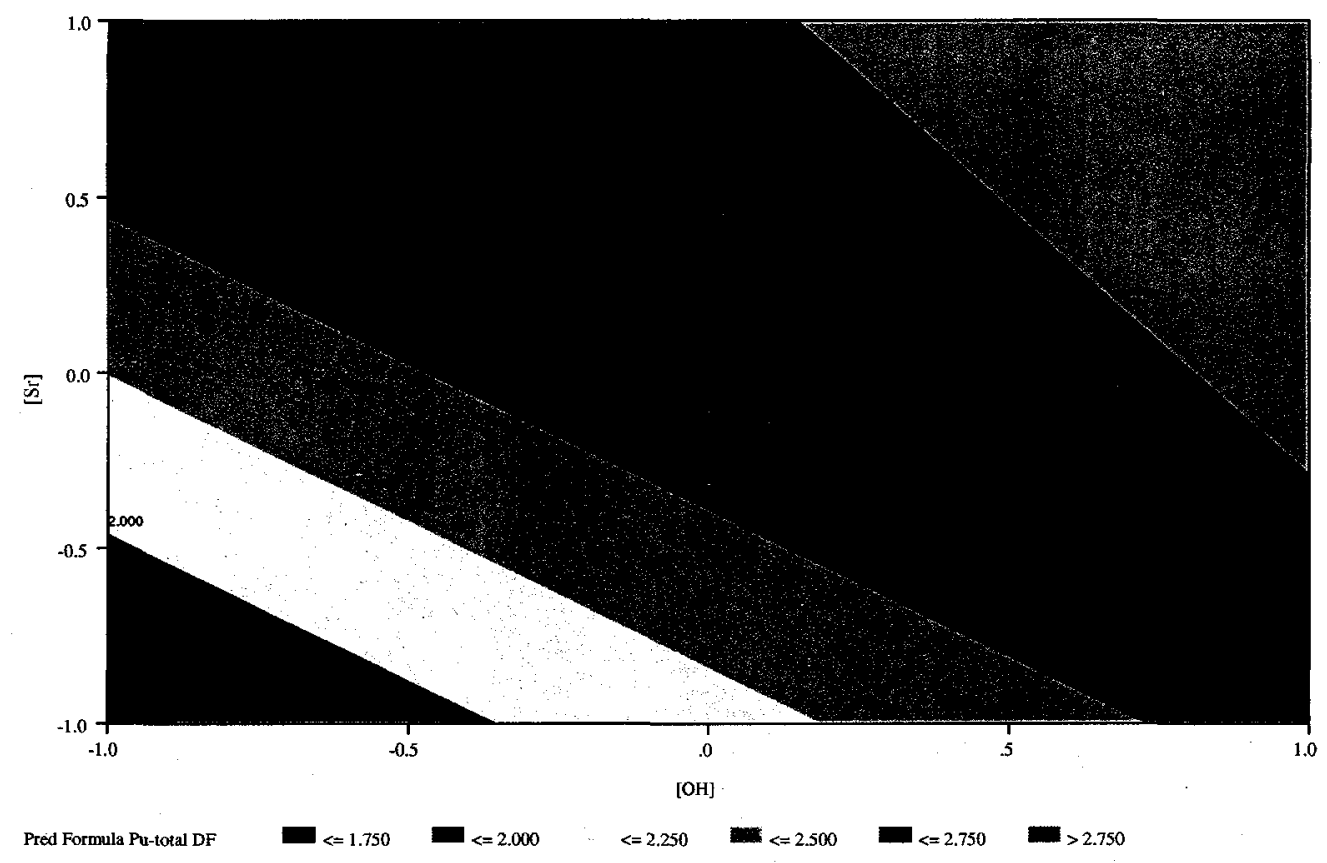

Figure 16. Contour Plot of $\mathrm{Pu} \mathrm{DF}$ as a Function of $\mathrm{Ca}$ and $\mathrm{Sr}$

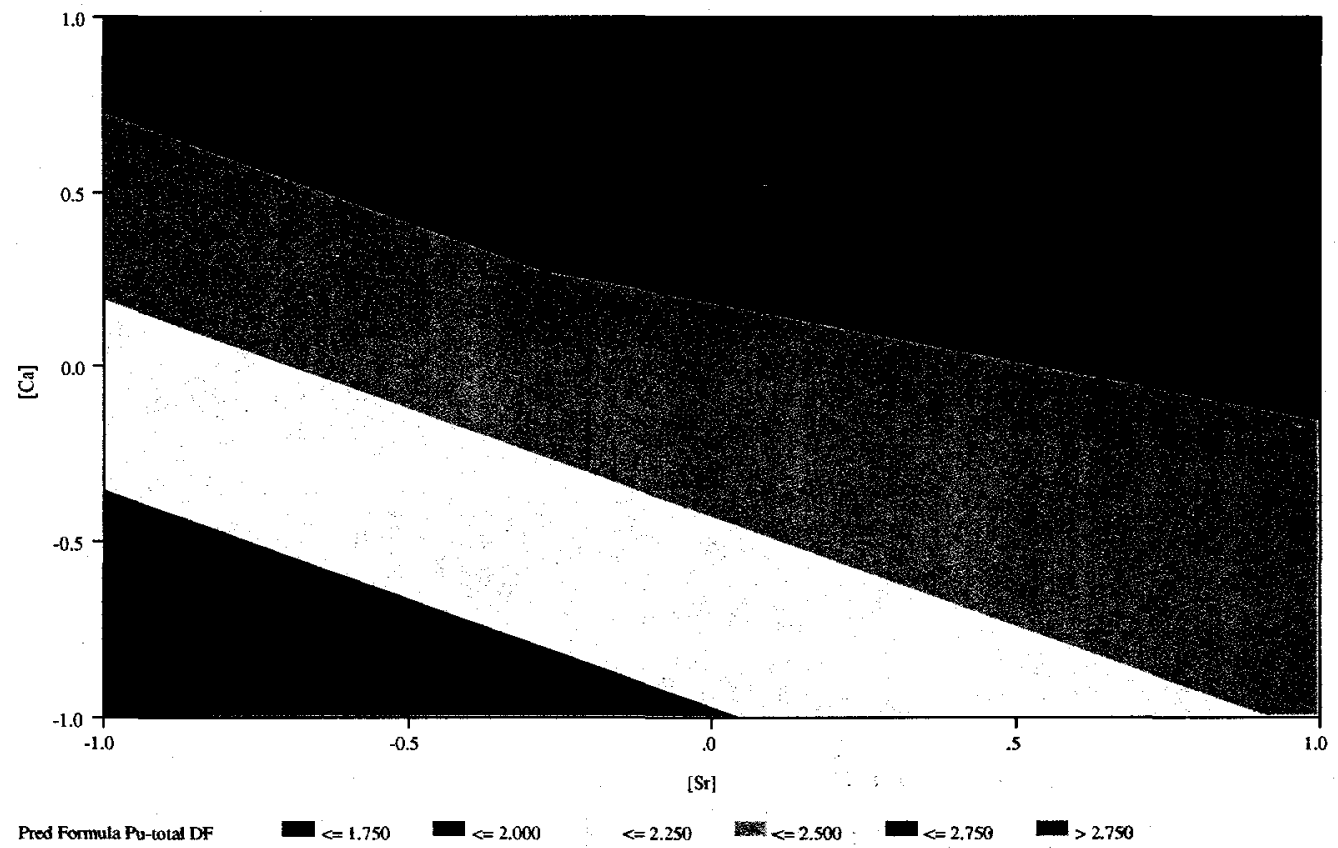


Plutonium DF Optimums

Based on the evaluation of the extremes and consideration of the contour plots a unified story emerges for the optimum conditions for $\mathrm{Pu} \mathrm{DF}$. This interpretation suggests the conditions presented in Table 17 are most beneficial for decontamination of plutonium. More specifically the results suggest that the hydroxide and sodium levels should be low and the strontium, calcium, and manganese concentrations should be at their high levels.

Table 17. Favorable Conditions for Pu DF

\begin{tabular}{llllll}
\hline & {$[\mathbf{O H}]$} & {$[\mathbf{N a}]$} & {$[\mathbf{C a}]$} & {$[\mathbf{S r}]$} & {$[\mathbf{M n}]$} \\
\hline Level & Low & Low & High & High & High \\
\hline
\end{tabular}

As a mean of cross checking the selected conditions for the optimum a cube plot is presented in Figure 17. This plot consists of a series of four three-dimensional plots. Each of these four plots shows the Pu DF response at each of the possible combinations of the extremes for the two parameters previously chosen to be fixed. Specifically, the four cubes are for the high Mn-high $\mathrm{Na}$, high $\mathrm{Mn}$-low Na, low Mn-high $\mathrm{Na}$, and low $\mathrm{Mn}$ Low Na conditions. The three axes in each cube depict the range for each of the remaining three variables. The predicted $\mathrm{Pu} \mathrm{DF}$ response is presented for the five variable conditions described at each corner of the four cubes.

Analysis of the cube plot supports the generalized conclusions gathered from the contour plots. In other words, the intersection of the low sodium-high manganese cube which corresponds to a high value of calcium, high value of strontium, and low value of hydroxide is predicted to be the best $\mathrm{Pu} \mathrm{DF}$ for the entire response surface. Observing that there are no other conditions noted on this series of cubes that provide a higher $\mathrm{Pu}$ decontamination further substantiates this conclusion. Furthermore, because the model contains no nonlinear terms the analysis can focus on the corners of the cube with a reasonable degree of certainty. 
Figure 17. Cube Plots for Pu DF

$[\mathrm{Mn}]=-1[\mathrm{Na}]=-1$

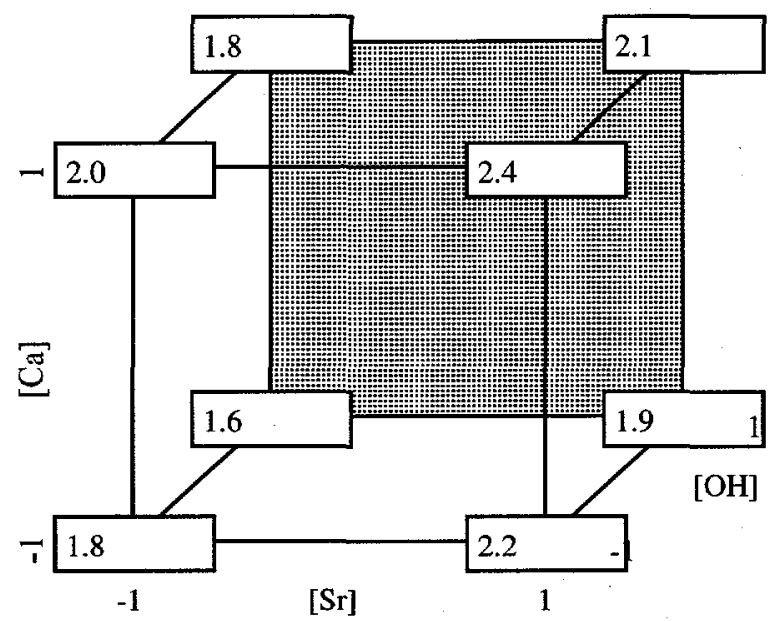

$[\mathrm{Mn}]=-1[\mathrm{Na}]=1$

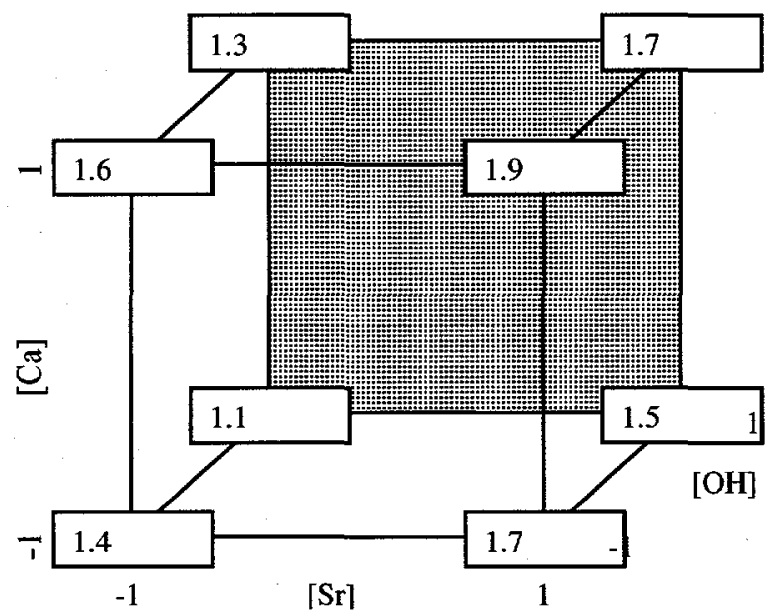

$[\mathrm{Mn}]=1[\mathrm{Na}]=-1$

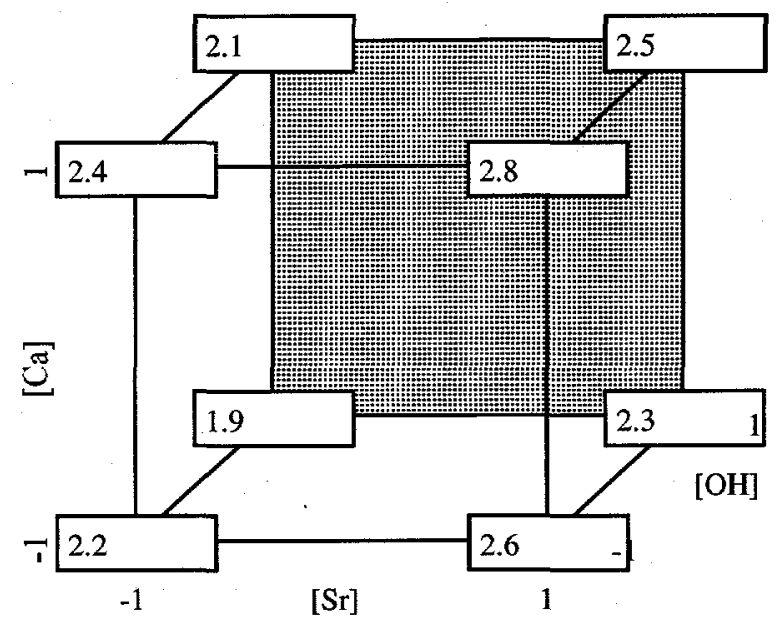

$[\mathrm{Mn}]=1[\mathrm{Na}]=1$

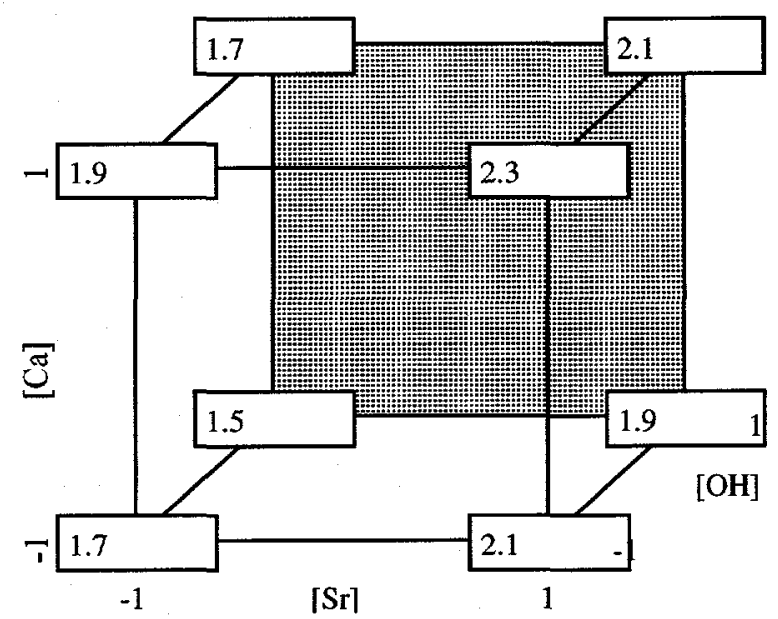




\section{Americium Decontamination}

\section{Americium DF Data}

Table 18 contains the Americium 241 (Am-241) decontamination factors determined from the precipitated and sheared 241-AN-102 samples. The americium concentration was measured using alpha-PHA counting for the initial feeds and the precipitated, sheared and filtered samples. The americium value used to calculate the decontamination factor was for the 241 isotope. The decontamination factor presented is calculated by simply comparing the ratio of the initial value of this activity to the activity in the final sample after pretreatment. For example if $50 \%$ of the activity were not present relative to the feed the accompanying DF would be two. This calculation does not take into account issues such as dilution involved in various activities such as compositing or precipitating. The worst case scenario in dilution of the final activity affiliated with addition of the precipitants is about $9 \%$.

\section{Americium Modeling}

The Am-241 decontamination results were used to perform a statistical analysis and the resulting model relating this DF of the precipitated slurry to the five precipitation parameters are provided in Table 19. The JMP Statistical program, version 3.2.2 was used to fit the data to a linear function of the five variables. Terms that contributed to the model with less than an $85 \%$ confidence were dropped from the model. This strategy allows only the terms that are most likely contributing to a physical description remain. Some primary terms must remain in the model even though their significance of contribution is much less than the $85 \%$ threshold. This retention of these parameters is necessitated by higher order terms of sufficient significance for retention that contain that variable of interest as one of the cross terms.

The values shown in Table 19 are the model estimates (coefficients) of the linear response model, the standard errors of the estimates, the statistical $t$ ratio's, and the significance levels. For a parameter to be statistically significant, the significance level should be less than or equal to 0.05 . The resulting model clearly describes the experimentally obtained Am-241 removal efficiency data well. This fit is evidenced by the residuals square. All terms are important at a 95\% confidence level with the exception of the primary sodium term that is retained for the previously discussed reason.

\section{Americium Extremes}

A strategy was developed to find the optimum Am DF response for the five variable parameter space examined. The method implemented for this evaluation consisted of several steps. The first was to plot the predicted decontamination as a function of the measured decontamination. These data points are shown in 18 as well as the associated 95\% confidence intervals (lines). The design numbers from Table 1 which correspond to the extremes are shown on the graph. The conditions afiliated with these extreme (highest 
and lowest) Am decontaminations were analyzed for opposing contribution to the observed decontamination effeciency.

Table 18. Calculated Am-241 Decontamination Factors

\begin{tabular}{|c|c|c|}
\hline SAMPLE ID & AM-241 DF & $+/-$ for $95 \%$ conf. \\
\hline BNFL-15B-EXP-1-B1 & 3.8 & 0.7 \\
\hline BNFL-15B-EXP-2-B1 & 3.1 & 0.6 \\
\hline BNFL-15B-EXP-3-B1 & 3.1 & 0.6 \\
\hline BNFL-15B-EXP-4-B1 & 3.0 & 0.6 \\
\hline BNFL-15B-EXP-5-B1 & 2.6 & 0.5 \\
\hline BNFL-15B-EXP-6-B1 & 2.4 & 0.5 \\
\hline BNFL-15B-EXP-7-B1 & 2.3 & 0.4 \\
\hline BNFL-15B-EXP-8-B1 & 5.1 & 1.0 \\
\hline BNFL-15B-EXP-9-B1 & 2.8 & 0.5 \\
\hline BNFL-15B-EXP-10-B1 & 2.4 & 0.5 \\
\hline BNFL-15B-EXP-11-B1 & 2.3 & 0.4 \\
\hline BNFL-15B-EXP-12-B1 & 4.0 & 0.8 \\
\hline BNFL-15B-EXP-14-B1 & 3.8 & 0.7 \\
\hline BNFL-15B-EXP-15-B1 & 2.9 & 0.5 \\
\hline BNFL-15B-EXP-16-B1 & 2.5 & 0.5 \\
\hline BNFL-15B-EXP-17-B1 & 2.9 & 0.5 \\
\hline BNFL-15B-EXP-18-B1 & 2.9 & 0.6 \\
\hline BNFL-15B-EXP-19-B1 & 5.5 & 1.0 \\
\hline BNFL-15B-EXP-20-B1 & 5.9 & 1.1 \\
\hline BNFL-15B-EXP-21-B1 & 4.7 & 0.9 \\
\hline BNFL-15B-EXP-22-B1 & 3.7 & 0.7 \\
\hline BNFL-15B-EXP-23-B1 & 2.9 & 0.6 \\
\hline BNFL-15B-EXP-24-B1 & 2.6 & 0.5 \\
\hline BNFL-15B-EXP-26-B1 & 2.1 & 0.4 \\
\hline BNFL-15B-EXP-14F5-B1 & 3.6 & 0.7 \\
\hline BNFL-15B-EXP-18F1-B1 & 1.7 & 0.3 \\
\hline BNFL-15B-EXP-27F4-B1 & 2.7 & 0.5 \\
\hline BNFL-15B-EXP-13R-B1 & 2.3 & 0.4 \\
\hline BNFL-15B-EXP-4R-B1 & 5.4 & 1.0 \\
\hline
\end{tabular}


Table 19. Statistical Analysis Results for Am-241 DF

$\begin{array}{lrrrr}\text { Term } & \text { Estimate } & \text { Std Error } & \text { t Ratio } & \text { Probe }>|\mathbf{t}| \\ \text { Intercept } & 3.3342887 & 0.157186 & 21.21 & <.0001 \\ {[\mathrm{MN}]} & 0.5221391 & 0.17508 & 2.98 & 0.0099 \\ {[\mathrm{Ca}]} & 0.2766949 & 0.172199 & 1.61 & 0.1304 \\ {[\mathrm{MN}]^{*}[\mathrm{Ca}]} & 0.3228814 & 0.190766 & 1.69 & 0.1127 \\ {[\mathrm{OH}]} & 0.3 & 0.199402 & 1.50 & 0.1547 \\ {[\mathrm{Ca}]^{*}[\mathrm{OH}]} & -0.2875 & 0.199402 & -1.44 & 0.1714 \\ {[\mathrm{Sr}]} & 0.1853814 & 0.190766 & 0.97 & 0.3477 \\ {[\mathrm{MN}]^{*}[\mathrm{Sr}]} & -0.335381 & 0.190766 & -1.76 & 0.1006 \\ {[\mathrm{Ca}]^{*}[\mathrm{Sr}]} & -0.515317 & 0.189747 & -2.72 & 0.0167 \\ {[\mathrm{NA}]} & -0.2875 & 0.199402 & -1.44 & 0.1714 \\ {[\mathrm{OH}]^{*}[\mathrm{NA}]} & -0.3 & 0.199402 & -1.50 & 0.1547 \\ {[\mathrm{Sr}]^{*}[\mathrm{NA}]} & -0.3625 & 0.199402 & -1.82 & 0.0905\end{array}$

Model Fit $\left(\mathrm{R}^{2}\right): 0.722923$

Figure 18. Predicted vs. Measured Am Decontamination Factors

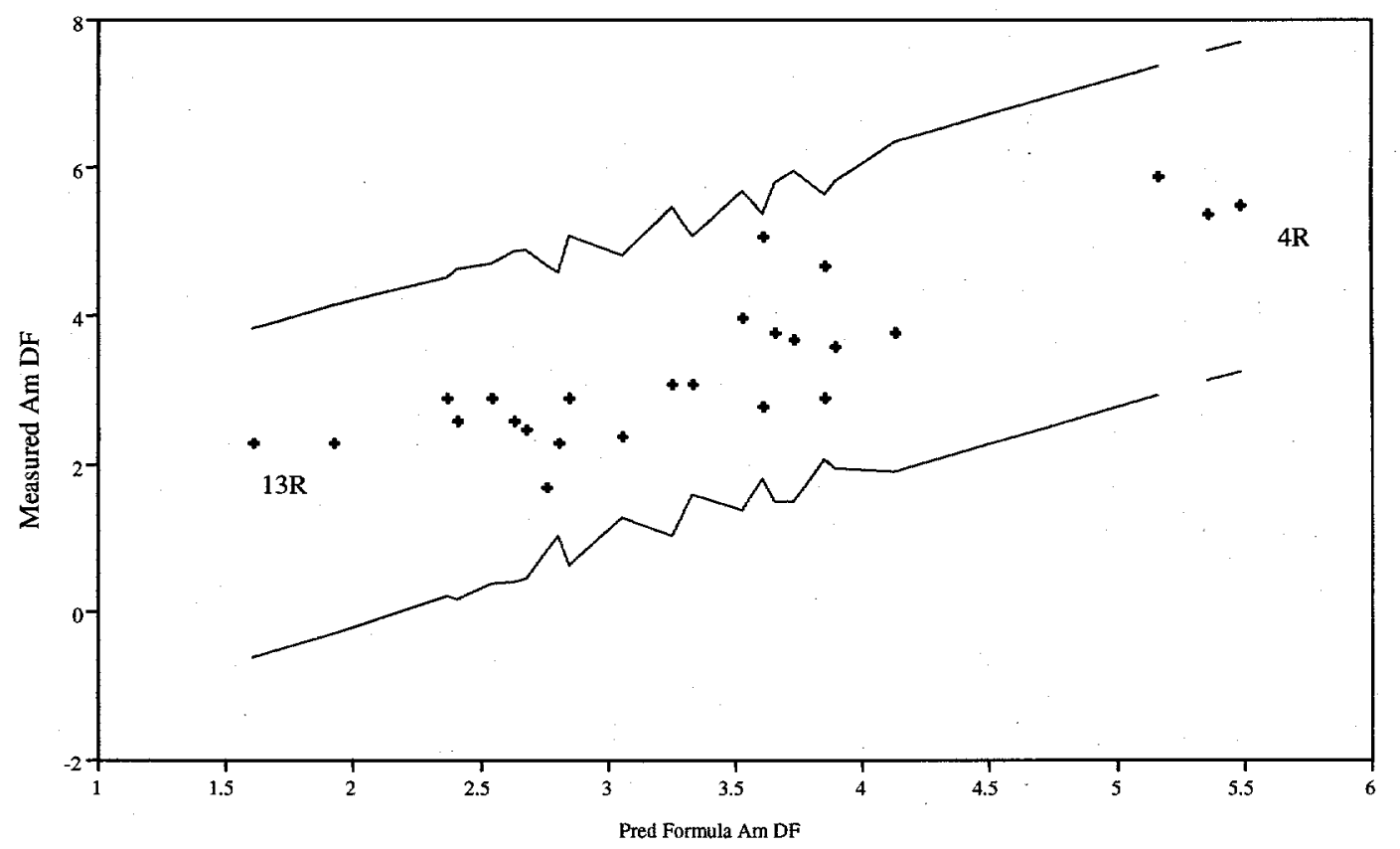


The conditions associated with the extremes for americium decontamination are shown in Table 20. By evaluating the conditions associated with the extremes it can be seen that the experimental conditions which yield the highest DF contained the high levels of manganese and calcium. On the other hand, the conditions affiliated with the low filterability extreme are opposite to those of the high extreme. Namely, the levels of manganese and calcium are low for the poor Am DF extreme. Once the opposing conditions associated with the extremes were identified these two variables were held constant and the effects of the other three variables were evaluated.

\section{Table 20. Parameter Levels for Extreme Am DF}

$\begin{array}{lccccc}\text { Extreme DF } & {[\mathbf{M n}]} & {[\mathbf{C a}]} & {[\mathbf{O H}]} & {[\mathbf{S r}]} & \text { [Na] } \\ \text { High } & 1 & 1 & 1 & -1 & -1 \\ \text { Low } & -1 & -1 & -1 & -1 & 1\end{array}$

\section{Americium DF Contour Plots}

Based on this evaluation a series of contour plots were constructed to examine the impact of the remaining parameters $(\mathrm{Sr}, \mathrm{OH}$, and $\mathrm{Na}$ ) while the levels of calcium and manganese were held at the preliminarily determined optimum. These three contour plots are shown in Figures 19-21. Figure 19 reveals that the most favorable levels are low for strontium while the level of hydroxide is not a factor in this parameter space. Figure 20 suggests that the levels of sodium and hydroxide should be at either opposite extremes or both at intermediate levels in order to produce the most favorable DF response for americium. Finally, Figure 21 shows that the level for strontium should be low while the impact of sodium concentration is negligible in this slice of the contour surface.

\section{Figure 19. Contour Plot of Am DF as a Function of $\mathrm{Sr}$ and $\mathrm{OH}$}

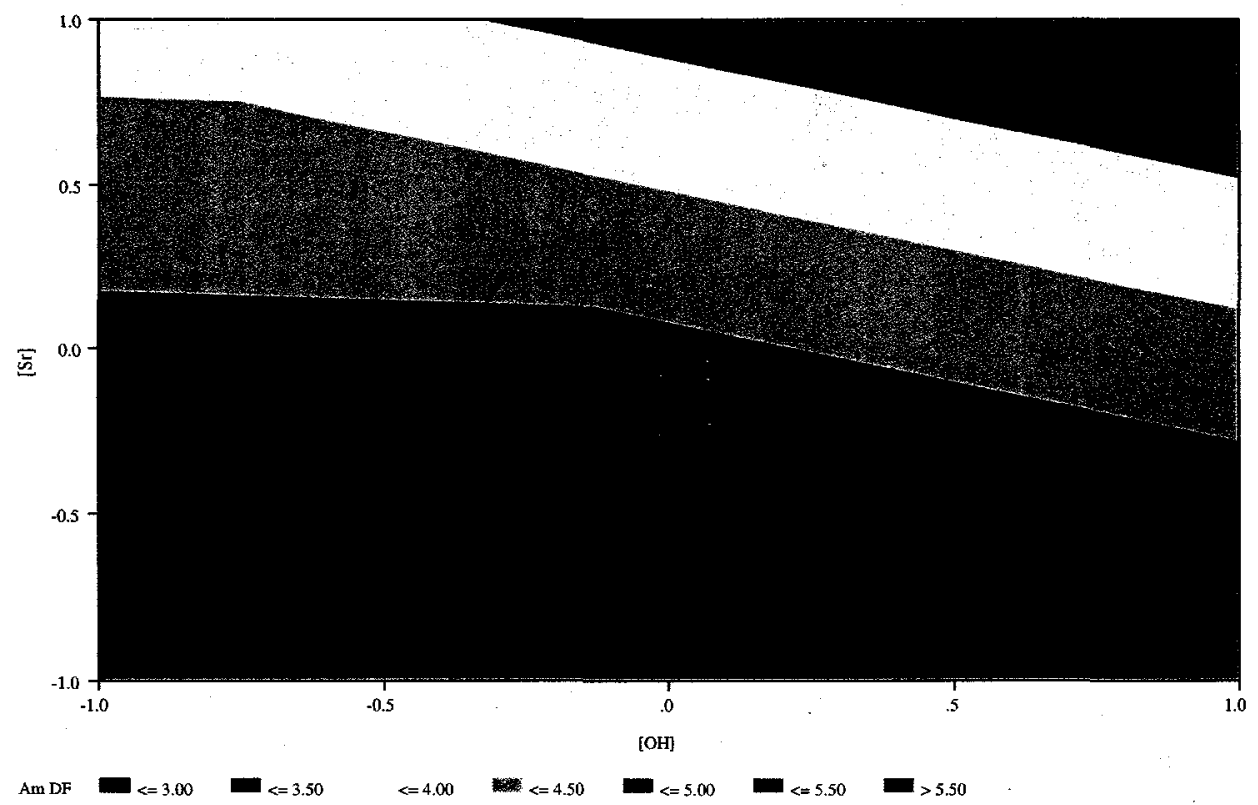


Figure 20. Contour Plot of Am DF as a Function of $\mathrm{Na}$ and $\mathrm{OH}$

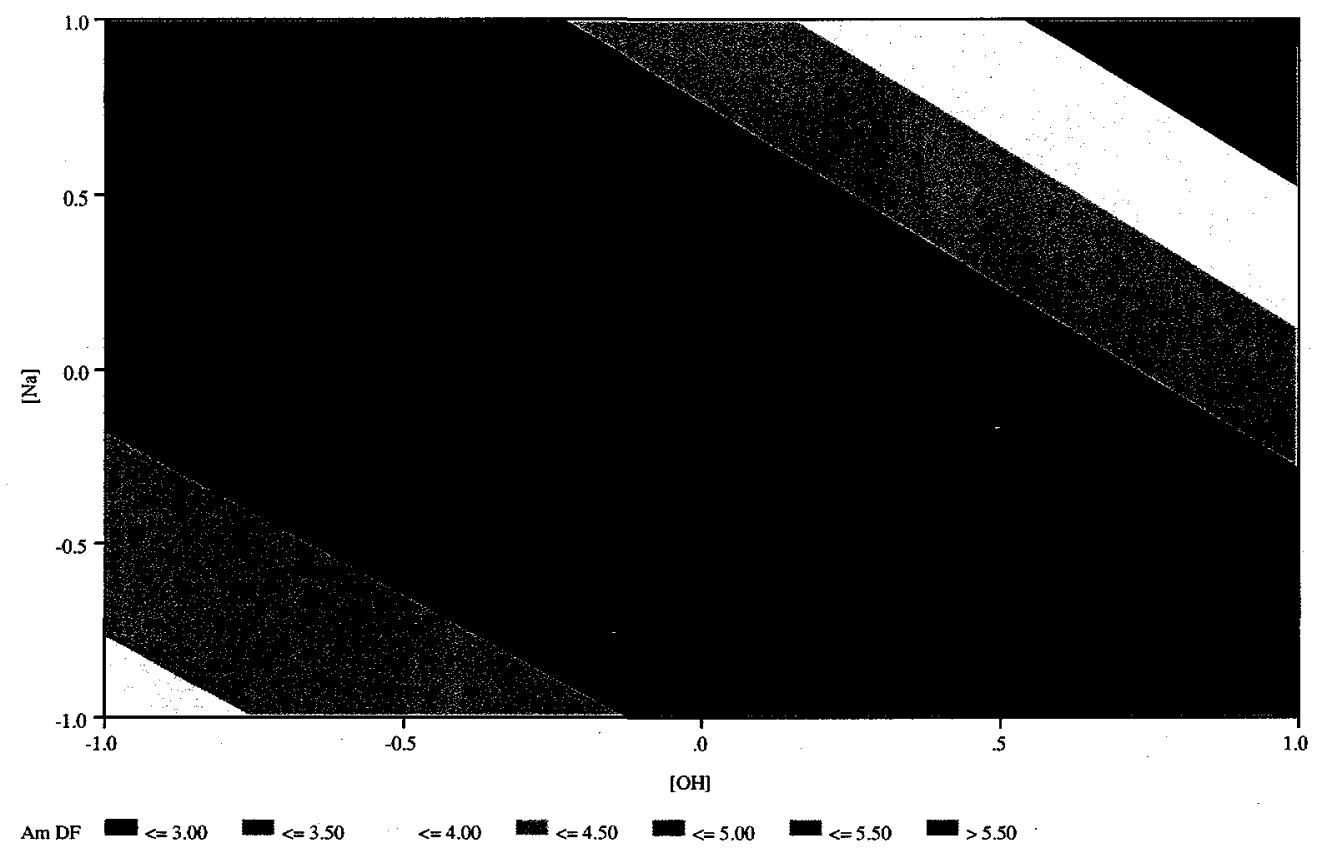

Figure 21. Contour Plot of Am DF as a Function of $\mathrm{Na}$ and $\mathrm{Sr}$

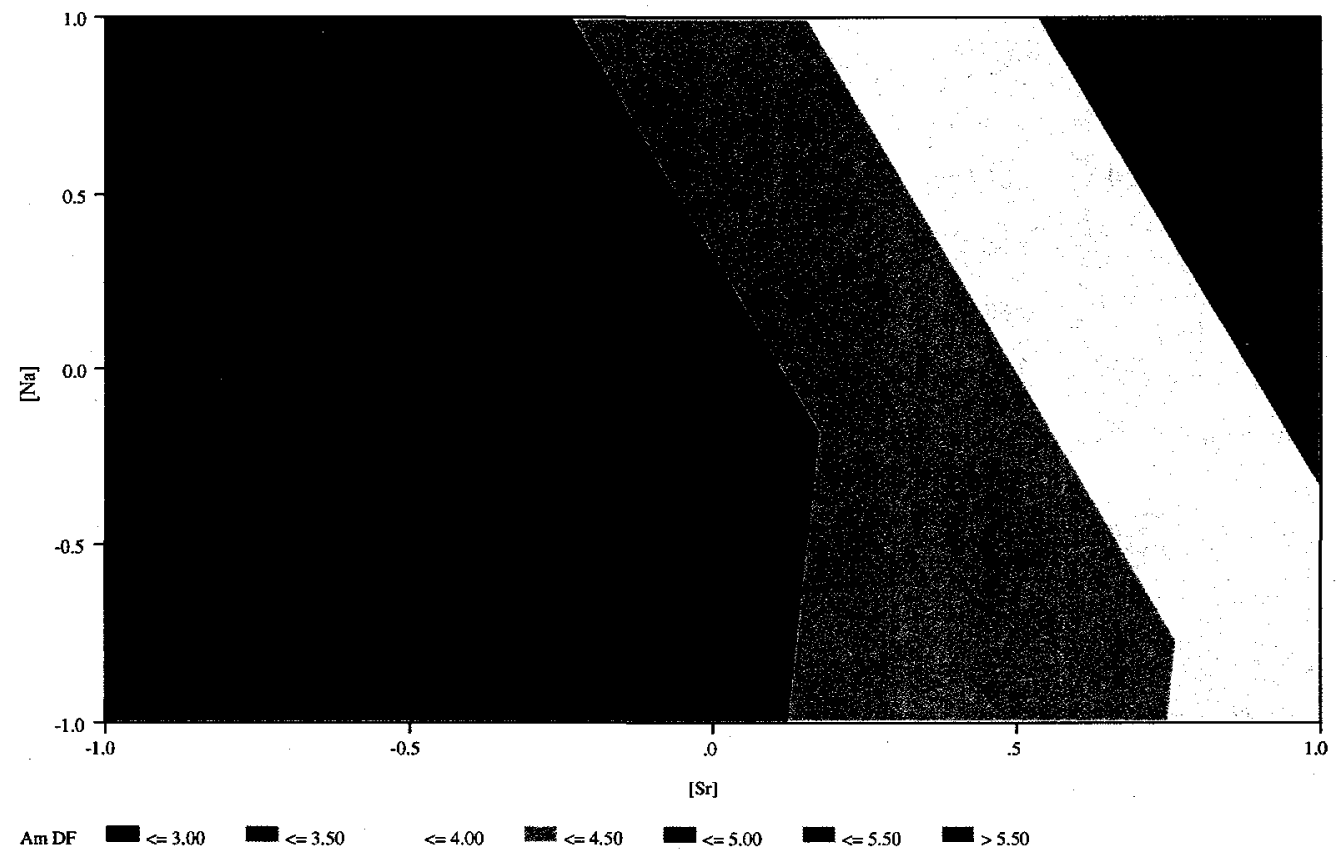


Americium DF Optimums

Based on the evaluation of the extremes and consideration of the contour plots a unified story emerges for the optimum conditions for Am DF. This interpretation suggests the conditions presented in Table 21 are most beneficial for decontamination of americium. More specifically the results suggest that the strontium level should be low and the calcium and manganese concentrations should be at their high levels. The most favorable Am DF occurs when the concentrations of sodium and hydroxide are opposing. Namely, either hydroxide is high and sodium is low or vice versa.

Table 21. Favorable Conditions for Pu DF

\begin{tabular}{cccccc}
\hline & {$[\mathbf{O H}]$} & {$[\mathbf{N a}]$} & {$[\mathbf{C a}]$} & {$[\mathbf{S r}]$} & {$[\mathbf{M n}]$} \\
\hline Level & Opposite of $\mathrm{Na}$ & Opposite of $\mathrm{OH}$ & High & Low & High \\
\hline
\end{tabular}

As a mean of cross checking the conditions for the optimum a cube plot is presented in Figure 22. This plot will assist in determining if either of the two possible combinations of the sodium and hydroxide levels is preferable. This plot consists of a series of four three-dimensional plots. Each of these four plots shows the Am DF response at each of the possible combinations of the extremes for the two parameters previously chosen to be fixed. Specifically, the four cubes are for the high $\mathrm{Mn}$-high Ca, high Mn-low Ca, low $\mathrm{Mn}$-high $\mathrm{Ca}$, and low Mn-Low Ca conditions. The three axes in each cube depict the range for each of the remaining three variables. The predicted Am DF response is presented for the five variable conditions described at each corner of the four cubes.

Analysis of the cube plot supports the generalized conclusions gathered from the contour plots. This plot also assists in revealing that the preferable levels for DF are low concentrations of sodium and high values for hydroxide. Realizing the DF for that combination is 4.40 while the DF for the opposing tandem is only 3.23 evidences this. Interestingly the intersection of the high calcium-high manganese cube which corresponds to a high value of hydroxide, low value of strontium, and low value of sodium is predicted to be the best Am DF for the entire response surface. However, the cube plot reveals that a slight modification to this conclusion should be made. Namely, that the most favorable conditions for americium removal are the above conditions with the exception of the strontium level being changed to high.

These results should be reviewed remembering that the data for the americium model was the most scattered of the data collected and resulted in a noticeable less intensive model. This observation is clearly substantiated by the difference in the americium model fit relative to the other three fits. Realizing the decontamination of plutonium and americium typically track one another suggests the high strontium level suggested by the cube plot is most applicable. Regardless of the strontium level, the previously described conditions for the other parameters in tandem with either the high or low levels of strontium still yield the essentially the highest decontamination even in the cube plot. This observation allows for confident reconciliation of this observed difference in strontium selection. 
Figure 22. Cube Plots for Am DF

$[\mathrm{Mn}]=-1[\mathrm{Ca}]=-1$

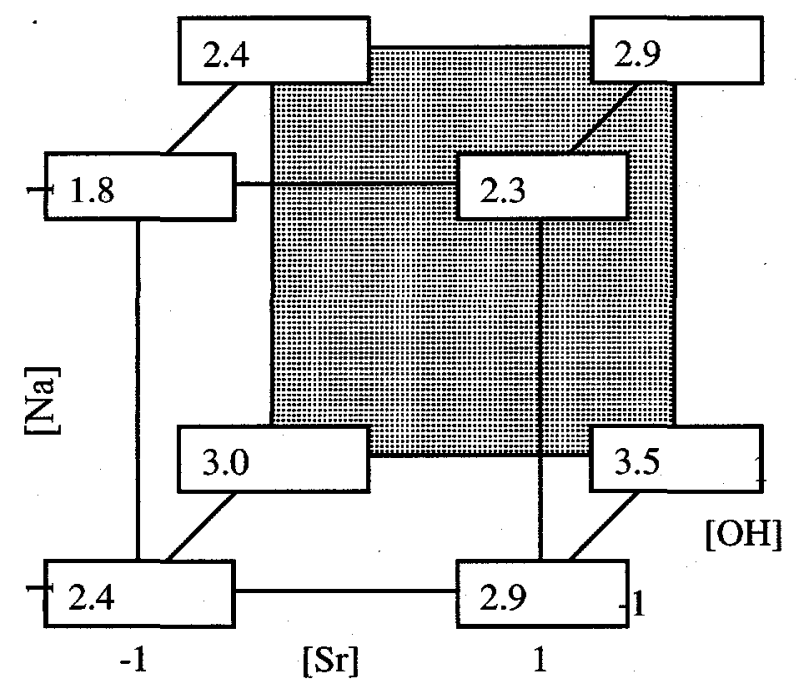

$[\mathrm{Mn}]=-1[\mathrm{Ca}]=1$

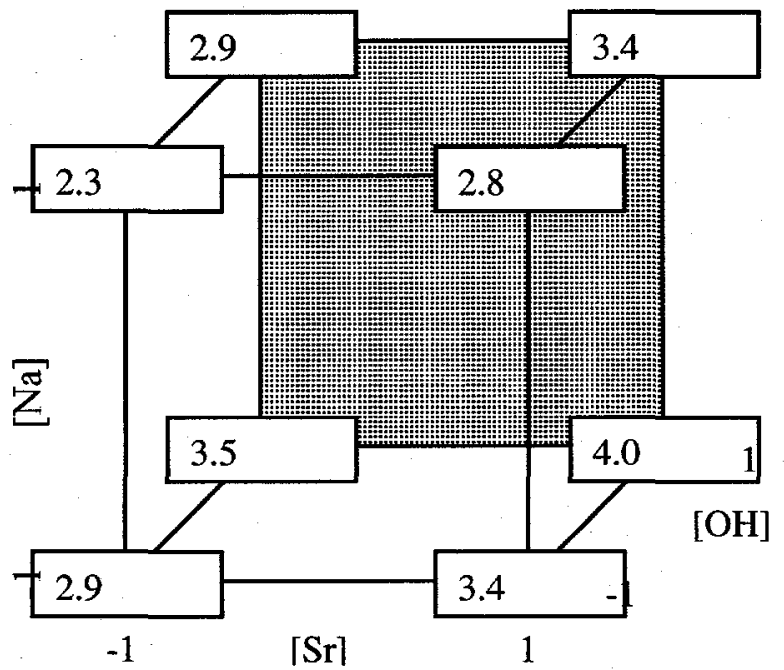

$[\mathrm{Mn}]=1[\mathrm{Ca}]=-1$

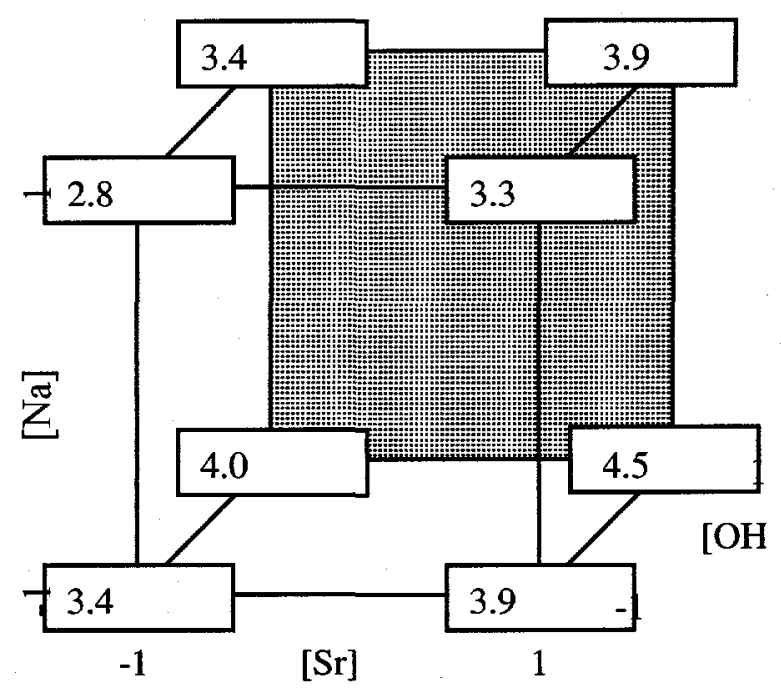

$[\mathrm{Mn}]=1[\mathrm{Ca}]=1$

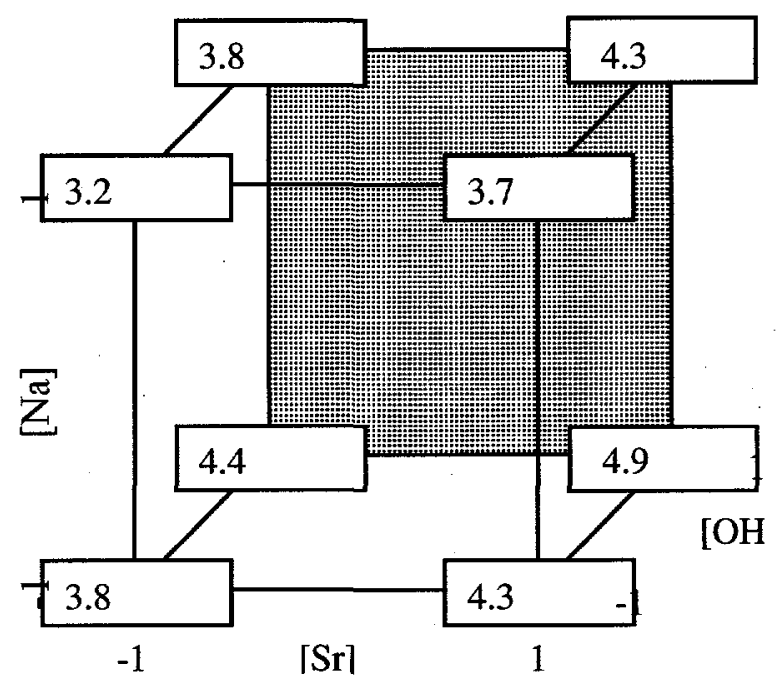




\title{
Unified Optimums for Precipitation Process
}

\section{Optimum Selection}

Unification of the results from the four individually determined models into one set of conditions for the five variables of interest with respect to the optimized process is the next area of investigation. The optimized process depends on filterability, Sr-90 decontamination and TRU decontamination.

The TRU decontamination in our case is the sum of $\mathrm{Pu}-238, \mathrm{Pu}-239, \mathrm{Pu}-240$, and $\mathrm{Am}-$ 241. The overall goal for TRU decontamination is to remove a sufficient amount such that the solution being transferred to the low-activity vitrification process will produce a glass with less than $100 \mathrm{nCi}$ of TRU per gram of glass. This limit translates into about $128 \mathrm{nCi}$ of TRU remaining in each milliliter precipitated waste in a $7 \mathrm{M}$ sodium solution as shown in Table 22. Note that the amount of TRU that is acceptable in the precipitated and filtered waste is a function of the amount of sodium as described in Table 22.

\section{Table 22. Limiting TRU Decontamination}

\author{
Glass \\ - Stated loading limit is $100 \mathrm{nCi} / \mathrm{g}_{\text {glass }}$ \\ - Glass is $20 \% \mathrm{Na}_{2} \mathrm{O}$ (17\% from waste) \\ - $1 \mathrm{gglass}=17 \% \mathrm{Na}_{2} \mathrm{O}_{\text {waste }} \times 46 / 62=.126 \mathrm{gNa}_{\text {waste }}$ \\ - Limit $=794 \mathrm{nCi} / \mathrm{gNa}_{\text {waste }}$ \\ Loading Limit

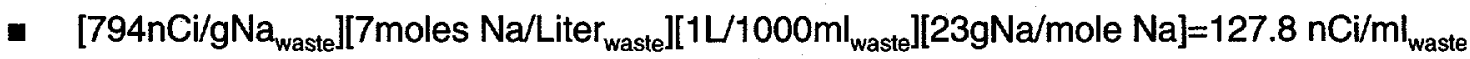

Shown in Table 23 is a summary of the observed optimum parameters for each of the four responses modeled. Realizing the three decontamination events are favored by high strontium addition as well as filterability it is clear that the high level for strontium addition unifies all four response optimums. This selection forces the manganese level to be high also. The only response for which this selection is not optimum is the $\mathrm{Sr}$ decontamination. This selection is more than acceptable due to the extremely high Sr-90 decontamination yielded by the process. All four responses of interest are best at the low level of sodium. The hydroxide level is chosen to be high for the unified optimum. This selection is justified by realizing that the plutonium decontamination response is not very sensitive to the value of this parameter. This selection is further justifiable based on the relation between criteria for overall TRU decontamination and the contribution to this total from americium relative to $\mathrm{Pu}$ constituents. Finally, the level of calcium should be 
chosen as a balance between the TRU decontamination responses and filterability. Increased calcium addition will favor TRU decontamination but hinder filterability. On the contrary, decreasing calcium addition favors filterability but decreases TRU decontamination. The resulting optimum parameters are summarized for this unified model in Table 24.

Table 23. Summary of Optimum Levels for Responses

\begin{tabular}{|l|c|c|c|c|}
\hline & Filterability & Pu DF & Am DF & Sr DF \\
\hline $\mathrm{OH}$ & High & Low & High & Any Value \\
\hline $\mathrm{Ca}$ & Low & High & High & Low \\
\hline $\mathrm{Na}$ & Low & Low & Low & Low \\
\hline $\mathrm{Sr}$ & Same as Mn & High & High & High \\
\hline $\mathrm{Mn}$ & Same as Sr & High & High & Low \\
\hline
\end{tabular}

Table 24. Unified Optimum Levels for Responses

\begin{tabular}{|l|c|}
\hline & Overall Process Response \\
\hline $\mathrm{OH}$ & High \\
\hline $\mathrm{Ca}$ & Low (Eillterability) or High(TRUDF's) \\
\hline $\mathrm{Na}$ & Low \\
\hline $\mathrm{Sr}$ & High \\
\hline $\mathrm{Mn}$ & High \\
\hline
\end{tabular}

Experimental Results at Unified Optimum Conditions

The results for a precipitation using the conditions of the unified optimum model are presented in Table 25. This data clearly shows that a high Sr-90 decontamination was achieved while maintaining an acceptable dead-end filter flux under these conditions. The plutonium and americium decontamination efficiencies are sufficient as evidenced by the total TRU value following precipitation. The TRU remaining in the glass is approximately about $50 \%$ lower than the necessary threshold for production of acceptable low-activity glass.

Specifically, the $44.2 \mathrm{nCi} / \mathrm{ml}$ value listed in Table 25 is composed of Pu-238, Pu-239, Pu240, and Am-241 activities. Due to NRC TRU definitions Cm-244 should also be added to this TRU activity summation. Previous analysis of the $\mathrm{Cm}-244$ activity of this tank demonstrate that the initial level of $\mathrm{Cm}-244$ is about $6-10 \mathrm{nCi} / \mathrm{ml}$ of waste. In the worst 
case, assuming no $\mathrm{Cm}-244$ decontamination, the total TRU activity remains below the $109.4 \mathrm{nCi} / \mathrm{ml}$ TRU decontamination threshold for producing non-TRU low-activity glass during the subsequent vitrification.

Likewise the Sr-90 remaining in the waste at a $95 \%$ confidence interval was $1.0 \pm 0.05$ $\mu \mathrm{Ci} / \mathrm{ml}$. This level corresponds to a decontamination factor of 65 as noted in Table 25 . The BNFL Inc. contractual limit for average Sr-90 in the Envelope C low-activity glass is less than $20 \mathrm{Ci} / \mathrm{m} 3$ in the glass. This $\mathrm{Sr}-90$ limit corresponds to $8.23 \mu \mathrm{Ci} / \mathrm{ml}$ in the pretreated Envelope $\mathrm{C}$ waste at $6 \mathrm{M} \mathrm{Na}$ and $17 \mathrm{wt} \%$ sodium oxide incorporation in the glass. The Sr-90 remaining in the waste is approximately $90 \%$ lower than the necessary threshold for production of acceptable low-activity glass from AN-102 waste.

The optimized model conditions recommend increasing the free hydroxide concentration in the 241-AN-102 Envelope $C$ wastes from $~ 0.15 \mathrm{M}$ to $1.0 \mathrm{M}$. Additionally, the conditions of the optimized model increase the nitrate concentration of the waste by $0.15 \mathrm{M}$ due to the strontium nitrate addition.

The BNFL Inc. process flowsheet specifies the use of SuperLig ${ }^{\circledR} 644$ and 639 resins to separate cesium and technetium from the low-activity waste solutions, following precipitation and filtration. Increasing the free hydroxide concentration to $1.0 \mathrm{M}$ is beneficial for the separations of cesium and technetium. Bray et. al. have demonstrated that the cesium distribution coefficient of SuperLig ${ }^{\circledR} 644$ resin is increased by a factor of 3 when the $\mathrm{pH}$ of contacting waste solution is increased from $\mathrm{pH} 12$ to $\mathrm{pH} 14 .{ }^{20}$ The small, amount of additional sodium added to the waste from increasing the free hydroxide concentration and addition of sodium permanganate are not expected to significantly affect cesium separation. This expectation is also based on the cesium distribution testing with SuperLig ${ }^{\circledR} 644$ resin and varying sodium concentrations as performed by Bray and coworkers. The potential affects of permanganate on the cesium ion exchange resin are going to explored further. ${ }^{21}$ Similarly, increasing the free hydroxide concentration to $1.0 \mathrm{M}$ and increasing the total nitrate concentration in the waste by $0.075 \mathrm{M}$ are not expected to significantly affect technetium separation using SuperLig ${ }^{\circledR} 639$ resin. ${ }^{22}$

Table 25. Experimental Responses at Unified Model Optimums

Limiting [TRU] for LL Glass at $6 \mathrm{M} \mathrm{Na:}$

$$
[\mathrm{TRU}]<109.4 \mathrm{nCi} / \mathrm{ml}
$$

At the optimum using actual waste:

$$
\begin{aligned}
& \mathrm{Sr}-90 \mathrm{DF}=65 \\
& \mathrm{Pu}_{\text {total }} \mathrm{DF}=2.1 \\
& \mathrm{Am}-241 \mathrm{DF}=5.9 \\
& \text { Dead-end filter flux }=.13 \mathrm{gpm} / \mathrm{ft}^{2} \\
& \text { Final }[\mathrm{TRU}]=44.2 \mathrm{nCi} / \mathrm{ml} \text { at } 6 \mathrm{MNa}
\end{aligned}
$$




\section{Precipitation Sequence Properties}

Metals removal at Optimum

The chosen precipitation scheme impact on the concentrations of various species such as iron, chromium, nickel, and aluminum is of importance. If removed during the precipitation scheme these metals will no longer be incorporated into the low-activity glass but will be transferred as a sludge to be incorporated into the high level glass. Removal of these species from the pretreated slurry by the precipitation scheme is somewhat undesirable. Obviously, the most desirable scheme will partition the metals preferentially towards the low activity waste vitrification process.

The effect of the optimum precipitation scheme on the previously mentioned elements is shown in Table 26. The results are shown in the form of decontamination factors. As a matter of reference a DF of 1 corresponds to no removal of the species of interest following precipitation and filtration. A DF of 1.5 corresponds to approximately a $30 \%$ removal to the sludge phase of the species of interest. The data in this table shows that the impact of the precipitation process on nickel, chromium, and aluminum is about a $30 \%-40 \%$ reduction. The precipitation removes about $80 \%$ of the initial iron and manganese concentrations in solution. It is important to keep in mind that the initial level of iron in solution is only about $.0003 \mathrm{M}$. The actual mass of iron transferred into the high-level vitrification system is small (mass of original manganese being precipitated is even smaller).

Table 26. DF for Various Metals at Unified Model Optimums

How does this precipitation scheme affect other metals in solution?

$$
\mathrm{Fe}, \mathrm{Cr}, \mathrm{Al}, \mathrm{Ni}
$$

At the optimum using actual waste:

$$
\begin{aligned}
& \mathrm{Fe} \mathrm{DF}=4.6 \\
& \mathrm{Cr} \mathrm{DF}=1.7 \\
& \mathrm{Al} \mathrm{DF}=1.5 \\
& \mathrm{Ni} \mathrm{DF}=1.4
\end{aligned}
$$




\section{Effect of Temperature on Process}

The role of slurry temperature during the precipitation process is a key process parameter to be considered. The ideal process would not be strongly influenced by small changes in the process temperature. On the larger scales fluctuations in slurry temperature are common. A relative insensitivity to temperature over a limited range is a crucial factor in determining the robustness of the precipitation process.

Two experiments were performed at different temperatures. The temperatures evaluated were $25 \mathrm{C}$ and $50 \mathrm{C}$. The concentrations of calcium, strontium, manganese, sodium and hydroxide are the same in both experiments. The responses are given in Table 27 with the $95 \%$ confidence limits given as determined.

Table 27. Effect of Temperature on Process Responses

\begin{tabular}{|l|c|c|c|c|}
\hline & Filterability & Pu-DF & Am-DF & Sr-DF \\
\hline BNFL-15B-EXP-10= 50 C & $15 \mathrm{ml}$ & $1.7+/-0.5$ & $2.4+/-0.5$ & $37+/-7$ \\
\hline BNFL-15B-EXP-26= 25 C & $16 \mathrm{ml}$ & $1.8+/-0.5$ & $2.1+/-0.4$ & $23+/-5$ \\
\hline & & & & \\
\hline
\end{tabular}

The data clearly shows that for the precipitation conditions implemented the process is robust with respect to the temperature changes examined. The filterability, plutonium $\mathrm{DF}$, and americium DF responses are independent of the process temperature. The strontium DF response, at the $95 \%$ confidence level, is minimally improved at the elevated temperature. Note the strontium DF is typically more than adequate and that the precipitant conditions used for these experiments are non-optimum. Furthermore, the very minimal effect of temperature on the strontium DF is collective evidence that the process is robust with respect to the temperature at which the precipitation occurs.

\section{Effect of Timing for Permanganate Addition}

The role of timing involved in the addition of the permanganate to the slurry during the precipitation process is another key process parameter to be considered. The ideal process would be robust with regard to this timing. If the process is influenced by changes in the timing of this addition at the bench scale this is an unfavorable characteristic. At the larger plant scale the timing often cannot be as precise as in the laboratory. Pipe lengths, pump efficiency and a myriad of variable process conditions are not conducive to extremely high reproducibility in the addition

The effect of the timing of the manganese addition was examined using two experiments. The only difference between the two experiments is that the later experiment did not introduce the manganese five minutes following the strontium strike. The manganese was not added until two hours into the aging process. The sample then was aged for two 
more hours thus keeping the total time from initiation to completion of the precipitation scheme constant. The concentrations of calcium, strontium, manganese, sodium and hydroxide are the same in both experiments. The responses are given in Table 28 with the $95 \%$ confidence limits given as determined. Note that the first experiment, BNFL15B-EXP-20 is performed using the standard timing sequence as discussed in the experimental section while BNFL-15B-EXP-27F4 was performed by delaying the permanganate addition for two hours.

Table 28. Effect of Timing on Process Responses

\begin{tabular}{|l|c|c|c|c|}
\hline & Filterability & Pu-DF & Am-DF & Sr-DF \\
\hline BNFL-15B-EXP-20= 50 C & $21.5 \mathrm{ml}$ & $2.1+/-0.6$ & $5.9+/-1.1$ & $65+/-13$ \\
\hline BNFL-15B-EXP-27F4= 50 C & $23.5 \mathrm{ml}$ & $2.0+/-0.5$ & $2.7+/-0.5$ & $87+/-17$ \\
\hline & & & & \\
\hline
\end{tabular}

The data show that for the precipitation conditions implemented the process is robust with respect to the timing of permanganate addition. The filterability, plutonium DF, and strontium DF responses are independent of the timing of the permanganate addition. The americium DF response, at the $95 \%$ confidence level, is improved by adding the permanganate at the typical time relative to delaying the introduction.

When interpreting the Am data in table 28 it is important to remember that the americium data has been demonstrated to possess significant scatter relative to the other analysis. For instance, experiments BNFL-15B-EXP-8 and BNFL-15B-EXP-9 are duplicates yet the calculated Am DF is not the same. In summary, despite the calculated confidence limits, which are based only on the analytical error, it is not possible to definitely conclude that the permanganate timing effects americium decontamination. Further work should be performed to evaluate this effect in terms of the Am DF.

\section{Effect of Entrained Solids on Precipitation Process}

The original DOE flowsheet for processing the entrained solids of the Envelope $C$ waste from Hanford involved a crossflow filtration step prior to precipitation of $\mathrm{Sr}$ and TRU elements. The entrained solids separated from this step were to be returned to the DOE for storage or, at DOE's discretion, combined wit the waste stream which would be incorporated into glass using the high level melter. As a precautionary evaluation the effect of entrained solids on the optimized precipitation scheme was evaluated.

These entrained solids evaluations were performed by using a series of tests in which the only variable was the entrained solids were not removed using a dead-end filtration prior to feed preparation for the precipitation experiments. The weight percent entrained solids was less than $0.5 \%$. Duplicate tests were performed and the results for several observables of interest are shown in Table 29. The concentrations of calcium, strontium, manganese, sodium and hydroxide for both experiments are those determined in Table 24 
to be optimum. The results available at the time of reporting are shown in table 29 with the $95 \%$ confidence limits given when determined. The data presented are averages of two experiments.

Table 29. Effect of Entrained Solids

\begin{tabular}{|l|c|c|c|}
\hline & Filterability & Pu-DF & Am-DF \\
\hline Entrained Solids Present & $25.2 \mathrm{~g}$ & 1.6 & 7.2 \\
\hline Entrained Solids Removed & $26.0 \mathrm{~g}$ & 1.2 & 7.8 \\
\hline Previous Beaker & $26.1 \mathrm{~g}$ & $2.1+/-0.6$ & $5.9+/-1.1$ \\
\hline
\end{tabular}

Overall one can conclude that there is not any evidence for a significant effect of entrained solids on the filterability, americium DF, and plutonium DF. It is important to realize that this observation is based on duplicate tests and dead-end filtration. The strontium DF data is expected to trend likewise and will be reported at a later time. This result has potentially favorable ramification on the overall precipitation scheme. Based on this observation, processing sequences can be flexible for the Hanford waste in situations where entrained solids are present. This robustness in the flowsheet is of potential value to the overall program.

\section{Conclusions}

A new precipitation scheme has been developed. This scheme implements a strontium isotopic dilution, a sodium permanganate oxidation, and under certain conditions addition of calcium. A series of statistically designed tests examined the relationship between four responses of interest and five precipitation parameters. The four responses of interest are precipitate filterability, strontium decontamination, americium decontamination and plutonium decontamination. The precipitation parameters that were varied were the initial sodium concentration of the waste, the initial hydroxide level of the waste, and the amounts of calcium, strontium, and permanganate introduced. Furthermore a series of experiments were performed to evaluate the impact of several other process parameters such as temperature, timing of permanganate addition, and presence of entrained solids on the proposed precipitation scheme.

Based on the statistically designed series of experiments a model was developed for each of the responses. The results extracted from the various filterability and decontamination models suggest the conditions necessary for an optimum performance. Following are the major conclusions for the conditions evaluated: 
- An optimized laboratory precipitation scheme has been determined.

- This optimized scheme has been demonstrated to provide sufficient decontamination for subsequent vitrification studies.

- Temperature has a minimal effect on filterability and decontamination of the slurry

- Entrained solids do not alter the filterability or decontamination thus allowing flexibility in the flowsheet.

- Removal of transition metals such as $\mathrm{Cr}, \mathrm{Ni}$, and $\mathrm{Al}$ is minimal

- Sodium should be at the lowest value tested (6M)

- Hydroxide should be at the highest level examined (1M)

- Strontium addition should be at the highest dose evaluated (0.075M)

- Permanganate should be the highest concentration of the matrix (0.05M)

- Calcium added is inversely proportional to filterability and directly proportional to TRU decontamination.

Overall, the process and chemical variables are better understood. The improved baseline flowsheet for Sr/TRU removal contains issues to be addressed. The effect of the permanganate addition timing on the Am DF should be explored in more detail.

Furthermore, experimentation to demonstrate acceptable filterability and decontamination using the more extreme conditions of crossflow to separate a larger volume of actual 241AN-102 envelope $C$ waste are necessary. The filtration work is currently ongoing and will be reported in a subsequent report. ${ }^{23}$

\section{Acknowledgements}

The authors wish to acknowledge the help and assistance provided by the Analytical Development Section in their analysis of the many samples submitted during this work.

\section{References}

1. M. J. Klein and W. G. Wilson, "Strontium Recovery from Purex Acidified Sludge," ARH-CD-691, May 1976.

2. D. J. McCabe, "Hanford Envelope Archive C Tank Waste Precipitation Study (U)," SRTC-BNFL-004, Revision 0, March 20, 1997.

3. D. J. McCabe, "Hanford C Tank Waste Precipitation Study (U)," SRTC-BNFL-005, Rev. 2, August 13, 1997.

4. D. J. McCabe, "Hanford Simulant Tank Waste Precipitation Study," SRTC-BNFL006, Rev. 0, April 22, 1997.

5. D. J. McCabe, "Hanford Envelope C Tank Waste Precipitation Optimization Study (U)," SRTC-BNFL-011, Rev. 0, August 13, 1997. 
6. D. L. Herting, "Report of Scouting Study on Precipitation of Strontium, Plutonium and Americium from Hanford Complexant Concentrate Waste," WHC-SD-WMDTR-040, Rev. 0, 1995.

7. R. J. Orth, A. H. Zacher, A. J. Schmidt, M. R. Elmore, K. R. Elliott, G. G. Neuenschwander, S. R. Gano, "Removal of Strontium and Tranuranics from Hanford Tank Waste via Addition of Metal Cations and Chemical Oxidant - FY1995 Test Results," PNL-10766, UC-721, September, 1995.

8. W. R. Wilmarth et al., "Phase I and II Results from Sr and TRU Precipitation Tests," BNF-003-98-0023, Rev. 0, September 15, 1999.

9. W. R. Wilmarth et al., "Transuranium Removal from Hanford AN-107 Simulants Using Sodium Permanganate and Calcium", BNF-003-98-0160, Rev. 0, September 30, 1999.

10. W. R: Wilmarth et al., "Task Technical and Quality Assurance Plan for Sr/TRU Precipitation of Hanford High Level Waste", BNF-003-98-0012, Rev. 3, June 11, 1999.

11. SAS Institute, Inc., "JMP Statistics and Graphic Guide," Version 3, SAS Institute, Inc., Cary, NC, 1994.

12. Statistical Consulting Section, "Software Verification and Validation for Commercial Statistical Packages Utilized by the Statistical Consulting Section of SRTC," WSRCRP-99-00422, Rev. 0, May 21, 1999.

13. M. S. Hay, "Task Technical and Quality Assurance Plan for Sample Characterization and Sludge Washing in Support of BNFL Part B", BNF-003-98-0013, Rev. 0, October 21, 1998.

14. “Obtaining Analytical Services, “Manual L1, Procedure 3.07, Rev. 0, August 6, 1993.

15. "Inductive Coupled Plasma - Emission Spectrometer for Aqueous Liquid Sample Analysis," Manual L16.1, Procedure ADS-1509, June 25, 1996.

16. "Inductively Coupled Plasma - Mass Spectrometer Elemental and Isotopic Analysis for Aqueous Liquid Sample Fisons PlasmaQuad II (U)," Manual L16.1, Procedure ADS1543, Rev. 1, April 1, 1998.

17. "Gamma Sample Preparation and Analysis (Gamma PHA)," Manual L16.1, Procedure ADS-2420, Rev. 3, July 28, 1997.

18. "Beta Liquid Scintillation Sample Preparation and Analysis, Manual L16.1, Procedure ADS2401, Rev. 3, March 20, 1997. 
19. "Alpha Pulse Height Analysis," Manual L16.1, Procedure ADS-2402, Rev. 2, July 25, 1994.

20. "Efficient Separations and Processing Crosscutting Program: Develop and Test Sorbents", L. A. Bray, et. al., PNL-10750, September 1995.

21. C.A. Nash and D.J. McCabe, "Task Technical and Quality Assurance Plan: Studies of Ion Exchange Resin Integrity under Flowsheet Extremes, BNF-003-98-00163, rev. 0, September 29, 1999.

22. IBC Advanced Technologies, Inc. has conducted batch contact tests with SuperLig ${ }^{\circledR}$ 639 resin and simulated waste solutions to evaluate the affect of various anions on the exchange of pertechnetate (IBC 1996). IBC personnel have demonstrated that hydroxide anion has no affect on the exchange of technetium with SuperLig ${ }^{\circledR} 639$ resin. Nitrate anion is the only anion commonly found in tank wastes (i.e., Cl, F, $\mathrm{SO}_{4}, \mathrm{OH}, \mathrm{NO}_{2}$ ) that affects the exchange of technetium with SuperLig ${ }^{\circledR} 639$ resin. However, the 241-AN-102 waste (as with most Hanford tank wastes) contains $1.86 \pm$ $0.2 \mathrm{M} \mathrm{NO}_{3}$ (for a $6 \mathrm{M} \mathrm{Na}$ solution), which by itself significantly reduces the exchange by of technetium with SuperLig ${ }^{\mathbb{B}} 639$ resin. The perrhenate (pertechnetate surrogate) equilibrium batch distribution coefficient for SuperLig ${ }^{\circledR} 639 \mathrm{resin}$ is $\sim 1 \mathrm{E}+05 \mathrm{ml} / \mathrm{gm}$ for a waste simulant that contains $5 \mathrm{M} \mathrm{OH}$ and no nitrate anion. However when this same waste simulant contains $2.1 \mathrm{M} \mathrm{NO}_{3}$ and $3 \mathrm{M} \mathrm{OH}$, the perrhenate equilibrium batch distribution coefficient for SuperLig ${ }^{\circledR} 639 \mathrm{resin}$ is decreased to $240 \mathrm{ml} / \mathrm{gm}$. Increasing the nitrate molarity by 0.15 from addition of strontium nitrate is not expected to significantly affect the exchange of technetium with SuperLig ${ }^{\circledR} 639$ resin since the waste already contains $1.94 \mathrm{M} \mathrm{NO}_{3}$ at $6.25 \mathrm{M} \mathrm{Na}$. (Supplied by M. Johnson of BNFL Inc.)

23. C.A. Nash, " Cells Unit Filter Operation Using Active Hanford Samples AN102 and AZ102", BNF-003-98-0113, rev. 0, July 12, 1999. 
Approvals:

Authors

S.W. Rosencrance

Date

Waste Processing Technology

R.A. Dewberry

Date

Analytical Development Section

D.P. DiPrete

Date

Analytical Development Section

T.B. Edwards

Date

Statistical Consulting

S.J. Emory

Date

Chemical Hydrogen Technology

C.A. Nash

Date

Waste Processing Technology

S.C. Smith

Date

Waste Processing Technology

W.R. Wilmarth

Date

Waste Processing Technology 
Design Check

M.S. Hay

Waste Processing Technology

Date

Management

S. T. Wach, Manager

Date

External Programs 